\title{
Preparation and Performance of a Biological Dust Suppressant Based on the Synergistic Effect of Enzyme-Induced Carbonate Precipitation and Surfactant
}

\section{Mingyue Wu ( $D$ Mywu1212@163.com)}

Shandong University of Science and Technology https://orcid.org/0000-0002-9667-0628

\section{Xiangming Hu}

Shandong University of Science and Technology

Qian Zhang

Shandong University of Science and Technology

\section{Yanyun Zhao}

Shandong University of Science and Technology

\section{Weimin Cheng}

Shandong University of Science and Technology

\section{Di Xue}

Shandong University of Science and Technology

\section{Research Article}

Keywords: surfactant, enzyme-induced carbonate precipitation, urease activity, wind and rain resistance, molecular simulation, dust consolidation

Posted Date: June 7th, 2021

DOl: https://doi.org/10.21203/rs.3.rs-518922/v1

License: (c) (i) This work is licensed under a Creative Commons Attribution 4.0 International License. Read Full License

Version of Record: A version of this preprint was published at Environmental Science and Pollution Research on September 6th, 2021. See the published version at https://doi.org/10.1007/s11356-02116307-x. 


\section{Abstract}

To control dust pollution caused by open-pit coal mining and reduce or avoid the secondary hazards of existing dust suppressants to the environment. A biological dust suppressant was prepared through the synergistic effect of surfactant and enzyme-induced carbonate precipitation. The optimal ratio of biological dust suppressant was determined, and the dust suppressive effect and dust-fixing mechanism of biological dust suppressant were studied. The results showed that when the concentration of alkyl glucoside (APG) was $0.3 \%$, the concentration of urea- $\mathrm{CaCl}_{2}$ was $0.6 \mathrm{~mol} / \mathrm{L}$, and the volume ratio of urease to urea- $\mathrm{CaCl}_{2}$ was $1: 3$, the wind erosion resistance of coal dust was enhanced by $86.69 \%$. The adsorption of biological dust suppressant and coal dust is mainly due to the electrostatic interaction between surfactant and coal dust. The mineralization product is calcite type $\mathrm{CaCO}_{3}$, and its can consolidate coal dust due to the formation of intermolecular hydrogen bonds between $\mathrm{CaCO}_{3}$ and coal dust.

\section{Introduction}

In recent years, with the progress of science and technology and the improvement of mechanical automation level, the production efficiency of the open-pit coal mine has been improved rapidly (DixonHardy et al., 2008). The concentration of dust in coal mining areas is also getting higher and higher, which makes it become the main pollution source of safe and efficient mining (Cui et al., 2011; Fan et al., 2018). Due to the characteristics of dust, it will not only affect the operation of mining facilities and pollute the surrounding environment of coal mines (Zhang et al., 2018), but also adversely affect the health of miners (Chang et al., 2019; Wang et al., 2019). Studies have shown that long-term exposure to high concentrations of coal dust has serious effects on the body, such as chronic stomach disease and noise induced deafness (Musselman et al., 2016; Zhang et al., 2019; Wang et al., 2020; Fu et al., 2021). This shows that the control of coal dust in open-pit coal mine is imminent.

With the increase in environmental protection, many companies have implemented coal dust control on open coal yards, such as spray method and dust suppressant method. However, due to the large difference in the degree of coal dust deterioration and particle size, water spraying is often ineffective, and the average dust reduction rate is less than 60\% (Ayoglu et al., 2014; Zhou et al., 2016). This is because the surface tension of water is high and it cannot quickly wet the coal dust. Adding some surfactants on the surface of coal dust can change the wettability of coal dust, make coal dust more hydrophilic, and improve dust reduction efficiency (Pollock et al., 2010; Cybulski et al., 2015; Yao et al., 2017). Although surfactants can be added to the water to achieve a good dust reduction effect, due to the lack of long-lasting inhibition and poor wind erosion resistance, multiple sprays are required, resulting in a lot of waste of water resources (Bao et al., 2020; Xu et al.82018; Northey et al., 2016). Domestic and foreign scholars have developed a variety of chemical dust suppressants, such as Medeiros et al. (2012) using biodiesel by-product glycerin to prepare dust suppressants. Xiao et al. (2015) prepared a new type of dust suppressant with strong hydrophobicity and high viscosity by copolymerizing carboxymethyl cellulose, acrylamide, and polyvinyl alcohol in a certain proportion. Dang et al. (2017) developed a co- 
polymer (gelatin and oxidized corn starch mixture) dust suppressant, and conducted dust removal experiments in a closed dust removal room. Although the prepared chemical dust suppressant can control coal dust pollution to a certain extent, it has disadvantages such as complicated preparation process, hard to degrade, and secondary pollution. Therefore, it is of great significance to find a dust suppressant that is simple to prepare and environmentally friendly.

Biologically induced calcite precipitation (EICP) is a green mineralization technology (Krajewska et al., 2018). In this technology, urea $\left(\mathrm{CO}\left(\mathrm{NH}_{2}\right)_{2}\right)$ is decomposed into carbonic acid $\left(\mathrm{H}_{2} \mathrm{CO}_{3}\right)$ and ammonia $\left(\mathrm{NH}_{3}\right)$ by urease. Ammonia forms ammonium $\left(\mathrm{NH}_{4}{ }^{+}\right)$in the water system, thus increasing the $\mathrm{pH}$ value of the solution (creating favorable conditions for carbonate precipitation). Carbonate precipitation can be produced in the presence of appropriate divalent cations (such as calcium). The reaction formula of this process is as follows (Hamdan et al., 2016).

$$
\begin{aligned}
& \mathrm{CO}\left(\mathrm{NH}_{2}\right)_{2}+2 \mathrm{H}_{2} \mathrm{O} \stackrel{\text { Urease }}{\longrightarrow} \mathrm{H}_{2} \mathrm{CO}_{3}+2 \mathrm{NH}_{3} \\
& \mathrm{H}_{2} \mathrm{CO}_{3} \rightleftharpoons \mathrm{HCO}_{3}^{-}+\mathrm{H}^{+} \\
& \mathrm{NH}_{3}+\mathrm{H}_{2} \mathrm{O} \rightleftharpoons \mathrm{NH}_{4}^{+}+\mathrm{OH}^{-} \\
& \mathrm{HCO}_{3}^{-}+\mathrm{OH}^{-} \longrightarrow \mathrm{CO}_{3}^{2-}+\mathrm{H}_{2} \mathrm{O} \\
& \mathrm{Ca}^{2+}+\mathrm{CO}_{3}^{2-} \longrightarrow \mathrm{CaCO}_{3}
\end{aligned}
$$

The $\mathrm{CaCO}_{3}$ produced by EICP technology has good compatibility with the environment. The generated calcium carbonate crystal plays two roles in the soil. Firstly, the calcium carbonate crystal fills the gaps between the soil particles, increases the compactness of the soil and the friction between the soil particles. Secondly, the calcium carbonate crystal has a cementation effect on the soil particles, which is equivalent to a binder to bond the small soil particles together. Therefore, it is favored by engineering experts. Hamdan et al. (2016) carried out a wind tunnel test on sand soil treated by EICP technology and proved that its dust suppression effect is better than that of traditional methods. Kavazanjian et al. (2017) confirmed that EICP technology can strengthen soil. Song et al. (2020) evaluated the inhibitory effect of EICP on fugitive dust and its impact on the stability of near-surface the soil. Wu et al. (2020) used EICP technology to effectively consolidate coal particles that passed a 40-mesh sieve. However, when the particle size of coal dust is small, its particle wettability is poor. When coal dust is consolidated using EICP technology, urease cannot penetrate into the coal dust, resulting in the $\mathrm{CaCO}_{3}$ produced unable to bind the coal dust particles together. If surfactants are added to urease, will it have a better consolidation effect on coal dust? In addition, the types and amounts of surfactants need to be further discussed.

Therefore, a biological dust suppressant based on the synergistic effect of surfactant and EICP technology was prepared. Firstly, the effects of cetyltrimethylammonium bromide (CTAB), sodium 
dodecyl sulfate (SDS), sodium dodecylbenzene sulfonate (SDBS), and alkyl glycoside (APG) on urease activity and coal wetting were studied. Then, the dust-holding performance of the biological dust suppressant was studied through the anti-evaporation and wind erosion resistance. Finally, through molecular dynamics simulation, microscopic image analysis (SEM-EDS), and phase analysis (XRD and FTIR), the dust-fixing mechanism of biological dust suppressants was studied. And the environmental protection of biological dust suppressant was analyzed.

\section{Materials And Methods}

\subsection{Materials}

First, the coal is crushed to screen out small particles of 120 mesh pulverized coal, using a fully automatic industrial analyzer (5E-MAG6600) conducted an industrial analysis of coal powder, as shown in Table S1. Then use a Malvern particle size analyzer (Mastersizer 3000) to analyze the particle size of the coal powder, as shown in Figure S1.

Cationic surfactants CTAB, anionic surfactants SDS, SDBS and non-ionic surfactants APG were purchased from Shanghai McLin Biochemical Technology Co., Ltd, China. Anhydrous calcium chloride and urea were purchased from Sinopharm Shanghai Reagent Co., Ltd, China.

Urease is extracted from yellow soybeans. It purchased from Daxinganling region, Heilongjiang Province, China. The detailed extraction method of urease in this study can be seen in the supporting information.

\subsection{Selection of surfactants}

\subsubsection{The effect of different surfactants on urease activity}

The activity of soybean enzyme was determined by the change of conductivity in solution. The decomposition of urea produces $\mathrm{NH}_{4}{ }^{+}$and $\mathrm{CO}_{3}{ }^{2-}$, and the conductivity increases with the increase of ion concentration in the solution. Therefore, urease activity can be reflected by the amount of urea decomposition. The detailed test method for urease activity can be seen in the supporting information. The relationship between the decomposition amount of urea and the change value of conductivity is as follows (Wu et al., 2020).

Urea hydrolyzed $(\mathrm{mmol} / \mathrm{L})=$ Conductivity change $(\mathrm{mS}) \times 16.81\left(\mathrm{R}^{2}=0.99897\right)(1)$

Cationic surfactants CTAB, anionic surfactants SDS, SDBS and non-ionic surfactants APG were selected to study the effects of different surfactants on urease activity, and the concentration of surfactant in the solution is $0,0.02,0.04,0.06,0.08,0.10,0.20,0.30,0.40$, and $0.50 \%$.

\subsubsection{Contact angle}


A FW-4A tablet press (Tianjin Tuopu Instrument Co., Ltd.) was used to press $0.5 \pm 0.02 \mathrm{~g}$ of pulverized coal into briquettes at a pressure of $25 \mathrm{MPa}$ and a pressing time of $3 \mathrm{~min}$. The Kruss DSA30 optical contact angle measuring instrument (Kruss, Germany) was used to measure the urease- $\mathrm{CaCl}_{2}$ solution ( $0.6 \mathrm{~mol} / \mathrm{L}$, in order to prevent urease from decomposing urea, the solution does not contain urea) containing different concentrations of surfactant in the briquettes. A camera was used to record the image $5 \mathrm{~s}$ after the drop of the liquid. The mass concentrations of different surfactants in the urease$\mathrm{CaCl}_{2}$ solution were $0,0.02,0.04,0.06,0.08,0.10,0.20,0.30,0.40$ and $0.50 \%$.

\subsubsection{Settlement test}

The device shown in Figure S2 was used to determine the sedimentation rate of pulverized coal. First, weigh $250 \mathrm{mg}$ of pulverized coal to form a conical coal pile on the surface of the filter paper through a glass funnel. Then, the filter paper is placed at the bottom of the metal ring and slowly brought into contact with the surfactant solution in the beaker using a lifting device. When the filter paper is in contact with the solution, it will absorb water and sink into the bottom of the urease- $\mathrm{CaCl}_{2}$ solution $(0.6 \mathrm{~mol} / \mathrm{L}$, in order to prevent urease from decomposing urea, the solution does not contain urea). At this time, record the time $t$ taken for the pulverized coal and the filter paper to completely settle to the liquid, and calculate the sedimentation rate of the pulverized coal. When the sedimentation time exceeds $1500 \mathrm{~s}$, it is considered that the surfactant at this concentration is not wetting (Chen et al., 2019), and will not be discussed further. The volume of the beaker is $1000 \mathrm{~mL}$, and the mass concentrations of different surfactants in the urease- $\mathrm{CaCl}_{2}$ solution are $0,0.02,0.04,0.06,0.08,0.10,0.20,0.30,0.40$ and $0.50 \%$.

The settlement rate is calculated by formula (2).

Settling rate $=\mathrm{M}_{0} / \mathrm{t}(2)$

Among them, $\mathrm{M}_{0}$ is the weight of coal dust, $250 \mathrm{mg}$; $\mathrm{t}$ is the time for the coal dust to settle completely, $\mathrm{s}$.

\subsection{Evaluation of the property of biological dust suppressant}

According to the original work done by the research group (Wu et al., 2020), the prepared biological dust suppressant contains urea, $\mathrm{CaCl}_{2}$, soy enzyme and surfactant as APG. Then, the method of using the biological dust suppressant is as follows: First spray the mixed solution of surfactant and urea-CaCl $\mathrm{C}_{2}$ and then spray the urease solution, as shown in Figure 1.

\subsubsection{Wind erosion resistance test}

First, the coal sample $(50 \pm 0.5 \mathrm{~g})$ was weighed in a disk (152 $\mathrm{mm}$ in diameter and $18 \mathrm{~mm}$ in height). Then, according to the formula in Table 1, the spray biological dust suppressor was prepared and sprayed on the surface of coal dust at room temperature. After $6 \mathrm{~h}$, the sample was placed in an oven with a temperature of $60{ }^{\circ} \mathrm{C}$, and the water on its surface was completely evaporated, and then sprayed with biological dust suppressant again for a total of 10 times. After spraying, the coal samples were placed in 
the oven to dry to a constant weight, and then tested for wind erosion resistance then tested. The wind speed of wind erosion resistance test is $5 \mathrm{~m} / \mathrm{s}, 10 \mathrm{~m} / \mathrm{s}$, and $15 \mathrm{~m} / \mathrm{s}$ respectively, and the time is $30 \mathrm{~min}$. Formula (3) is used to calculate the weight loss of the coal sample in the wind erosion test.

Mass loss $=M_{0}-M_{v}(3)$

Among them, $M_{0}$ is the weight of the sample before the wind erosion test, $g ; M_{v}$ is the weight of the sample after the wind erosion resistance test under different wind speeds, $\mathrm{g}$.

\subsubsection{Evaporation resistance test}

First, the coal sample $(40 \pm 0.5 \mathrm{~g})$ was weighed in a disk (100 $\mathrm{mm}$ in diameter and $20 \mathrm{~mm}$ in height). Then, according to the formula in Table 2, the spray biological dust suppressor was prepared and sprayed on the surface of coal dust at room temperature. After $6 \mathrm{~h}$, the sample was placed in an oven with a temperature of $60{ }^{\circ} \mathrm{C}$, and the water on its surface was completely evaporated, and then sprayed with biological dust suppressant again for a total of 10 times. Weigh the sample after drying and record it as $W_{0}$. Then, all the samples are completely wetted, and the weight of the coal sample after moisture absorption is recorded $\left(W_{1}\right)$. Finally, put the sample in a constant temperature and humidity oven (Figure S3) with a temperature of $25^{\circ} \mathrm{C}$ and a relative humidity of 40,60 , and $80 \%$, and take it out after a certain period of time for weighing, which is recorded as $W_{2}$. Evaporation resistance is expressed as a percentage of the moisture content in the sample.

The moisture content of the sample is calculated by formula (4).

$$
\text { Moisture content }=\frac{W_{1}-W_{2}}{W_{0}}
$$

\subsection{Molecular dynamics simulation}

Materials Studio 2018 software was used for molecular dynamics simulation. All the simulations were carried out under compass II force field. In this paper, APG molecular model (as shown in Figure 2a) and bituminous coal molecular model (Wiser model, as shown in Figure 2b) are used for simulation in APGwater-coal simulation system.

An APG-water-coal simulation system (Figure 2c) was constructed using the Amorphous cell module and Build Layers tools (Guo et al., 2018). Firstly, the APG, water and coal molecular models were optimized using the geometric optimization method in the Forcite module. Secondly, according to the density of APG, water and coal molecules at normal temperature and pressure, the amorphous unit cells of coal, APG and water were established using the Amorphous cell module. Then, the monomer (coal molecule, water molecule and APG of different molecular chains) is randomly integrated into the rectangular simulation box through the "building layer" tool, which is set periodically to form the APG coal water simulation system with different APG concentrations, as shown in Table 3. And a $20 \AA$ vacuum layer was 
also established on the top layer of the simulation box. Finally, in order to achieve structural relaxation, an annealing treatment was performed.

All MD simulations are performed in the Forcite module. First, the isothermal and pressure system (NPT) was selected to perform MD calculations at 50 ps. Then, 200 ps molecular dynamics calculations were performed on the system in a $298 \mathrm{~K}$ canonical system (NVT) to achieve complete relaxation of the system (Meng et al., 2019), and the final result was obtained.

\subsection{Microscopic morphology and phase analysis}

First, use a graduated cylinder to take urease solution $(10 \pm 0.1 \mathrm{~mL})$ and urea- $\mathrm{CaCl}_{2}(30 \pm 0.1 \mathrm{~mL}, 0.6 \mathrm{~mol} / \mathrm{L})$ solution in a beaker for mineralization. After the mineralization is complete, centrifuge the mineralized product in a centrifuge at $8000 \mathrm{rpm}$ for $10 \mathrm{~min}$. Then the centrifuged mineralized product was washed three times with deionized water and absolute ethanol each. Finally, the cleaned mineralized product is dried in a drying oven at $60{ }^{\circ} \mathrm{C}$ until the weight change is not more than $0.1 \%$.

The Rigaku Utima IV X-ray diffractometer (Thermo Fisher Scientific, Japan) was used to test the mineralized products, samples $\mathrm{R}$ and $\mathrm{A}-2$, with a scanning range of $15-85^{\circ}$ and a scanning speed of 10 $\%$ min.

The APREO field emission scanning electron microscope (FEI, USA) was used to observe the microscopic morphology and EDS analysis of the mineralized products and the samples in section 2.3.1. Among them, samples were taken on the surface and bottom of samples A-1, A-2 and A-3.

A Nicolet iS50 FTIR Fourier Infrared Spectrometer (Thermo Fisher Scientific, USA) was used to test the mineralization products, samples $R$ and $A-2$, and the wavenumber range was $4000 \sim 500 \mathrm{~cm}^{-1}$.

\section{Results And Discussion}

\subsection{Selection of surfactants}

\subsubsection{The effect of different surfactants on urease activity}

The determination of surfactant type is the key of urease to play its role. Figure 3 shows the effects of different surfactants on urease activity. It can be seen from the figure that CTAB has a strong inhibitory effect on urease activity, that is, the amount of urea decomposition is small, SDBS and SDS have a smaller inhibitory effect on urease activity than CTAB, and there is little difference between SDBS and SDS. While APG hardly affects urease activity, the amount of urea decomposition at this time is close to $25 \mathrm{mmol} / \mathrm{L}$.

The effect of surfactant on urease activity is attributed to the electrostatic interaction between surfactant and urease and the electrostatic potential generated by surfactant. Anionic/cationic surfactants ionize ions in aqueous solutions. If the ionic strength is too high, its charge will change the spatial structure of 
the protein, thereby reducing the urease activity. In addition, the hydrophobic groups of anionic/cationic surfactants may enter the active center of the urease molecule to form a complex, which will deactivate the urease. Non-ionic surfactants have almost no effect on urease activity because they cannot ionize charges in the solution.

\subsubsection{Contact angle}

Figure 4 shows the contact angles of biological dust suppressants with different concentrations of surfactants. It can be seen from the figure that for biological dust suppressants containing the same surfactant, as the concentration of the surfactant increases, the contact angle shows a gradual decrease trend. And when the concentration is lower than $0.1 \%$, the contact angle decreases faster, and when the concentration is greater than $0.1 \%$, the contact angle decreases gradually. This is due to the existence of

various adsorption sites in coal. When the surfactant concentration is low, the surfactant is not enough to occupy all the adsorption sites in the coal (Guo et al., 2018). Therefore, the contact angle drops faster. When the concentration of the surfactant in the biological dust suppressant gradually increases, the adsorption sites in the coal are gradually occupied, resulting in a smaller decrease in the contact angle. For different types of surfactants, when the concentration of APG, CTAB, SDBS, and SDS increases from 0 to $0.5 \%$, their contact angles on the briquettes surface decrease by $51.8^{\circ}, 39.9^{\circ}, 47.2^{\circ}$, and $43.7^{\circ}$, respectively. Among the four types of surfactants, CTAB has no obvious wetting effect on coal. This is because cationic surfactants will form an arrangement of hydrophobic groups facing outwards and hydrophilic groups facing inward on the surface of the liquid, resulting in poor wettability.

\subsubsection{Settling rate of coal dust}

The sedimentation process of coal dust is shown in Figure S4. It can be obviously seen in Figure 5 that as the concentration of APG, SDS, and SDBS in the biological dust suppressant increases, the sedimentation rate of coal dust gradually increases. The sedimentation rate of coal dust in the dust suppressant containing CTAB is the slowest. Only when its concentration is $0.3 \%$ can more obvious sedimentation be observed. This shows that the wettability of cationic surfactants to coal dust is the worst. When the SDBS concentration is $0.02 \%$, it can be seen that the sedimentation rate of coal dust is relatively fast, indicating its excellent wetting performance. In addition, it can also be seen from the figure that the wetting effect of biological dust suppressants containing SDS and APG on coal dust is relatively small.

Considering the influence of surfactants on urease activity, contact angle, and sedimentation rate of coal dust, APG was selected for research in the following tests.

\subsection{Evaluation of the dust-fixing performance of biological dust suppressants}

\subsubsection{Wind erosion resistance}

When the biological dust suppressant is sprayed, the mineralization products will be deposited in the coal dust, and then the coal dust will be consolidated. Figure 6 shows the surface morphology of coal dust after spraying 1, 5, and 10 times respectively. It can be seen from the figure that there is no obvious 
change on the surface of the coal dust after spraying once. After spraying 5 times, there are some white substances on the surface of samples $A-1, A-2$, and $A-3$, and these white substances become more obvious as the number of spraying increases. After spraying 10 times, the surface of the coal powder was almost covered with a layer of white material. On the surface of samples $R$ and $A-0$, no white matter appeared.

The weight loss of the sample at different wind speeds indicates the resistance to wind erosion. It can be seen from Figure 7 that as the wind speed increases, the weight loss of all samples shows an increasing trend. The weight loss of sample $R$ is the largest under different wind speeds $(7.83,15.33$, and $31.03 \mathrm{~g}$ respectively). When the wind speed of sample A-1 is $15 \mathrm{~m} / \mathrm{s}$, the weight loss even exceeds that of sample $\mathrm{A}-0$. The reason for this phenomenon is that as the wind erosion time increases, the consolidation layer on the surface of sample A-1 is gradually eroded, while the coal dust under the consolidation layer is not effectively consolidated. At this time, the unconsolidated coal dust is exposed to the wind current, which causes the weight loss of the sample to increase. Although urease was not added to sample A-0, with the extension of wind erosion time, $\mathrm{CaCl}_{2}$ in coal dust absorbed moisture in the air, leading to moisture on the surface of coal dust and increased resistance between pulverized coal particles, resulting in a smaller final weight loss than sample $\mathrm{R}$.

The weight loss of samples A-2 and A-3 is small (both are lower than $5 \mathrm{~g}$ ), which shows that both can be effectively consolidated. However, some samples in A-2 also appeared similar to A-1 when the wind speed was $15 \mathrm{~m} / \mathrm{s}$. That is, a small amount of coal powder at the bottom of the sample (far less than A1) was not effectively consolidated. When the wind speed is $15 \mathrm{~m} / \mathrm{s}$, the wind erosion resistance of samples A-1, A-2, and A-3 are increased by $51.66,86.69$, and $94.10 \%$, respectively. Taking into consideration the consolidation effect and the cost of the dust suppressant, the APG concentration is $0.3 \%$.

\subsubsection{Evaporation resistance}

Figure 8 shows the evaporation resistance results of the samples after different treatments. It can be observed from Figure 8 that when the temperature is $25^{\circ} \mathrm{C}$ and the humidity is $40 \%$, the water content in the sample gradually decreases with time. In particular, the moisture content of sample $\mathrm{R}$ dropped sharply, and it decreased by $16.44 \%$ within $12 \mathrm{~h}$. Although water containing APG can penetrate into the coal dust after spraying, the molecular structure of coal has a certain degree of hydrophobicity. When the environmental humidity is low, a large amount of water evaporates. The water content of samples $S$ and T reduced by $8.38 \%$ and $9.52 \%$ in $12 \mathrm{~h}$, respectively. This is because $\mathrm{CaCl}_{2}$ has a certain degree of water retention, and part of the $\mathrm{CaCl}_{2}$ in the samples sprayed with biological dust suppressants is mineralized, resulting in a slight decrease in water retention. When the humidity is 60 and $80 \%$, the moisture content of sample $\mathrm{R}$ hardly changes. While the samples $\mathrm{S}$ and $\mathrm{T}$ can absorb the moisture in the environment under the action of $\mathrm{CaCl}_{2}$ when the environmental humidity increases, resulting in an increase in the moisture content. Even at the end of the test, the moisture content in the sample is greater than the initial moisture 
content (48.18 and $47.36 \%$, respectively), which indicates that the biological dust suppressant has good anti-evaporation properties.

\subsubsection{XRD characterization}

Figure 9 shows the XRD patterns of mineralized products, samples $R$ and A-2. It can be seen from the FTIR spectrum of sample R that the coal powder contains a large amount of non-crystalline substances, which also contains a small number of crystalline substances such as quartz, kaolinite and other minerals. The XRD pattern of the mineralized product shows that the $2 \theta$ are $29.3^{\circ}, 36.1^{\circ}, 39.4^{\circ}, 43.1^{\circ}$, and $47.4^{\circ}$, which are characteristic diffraction peaks of $\mathrm{CaCO}_{3}$, and they are of calcite type. In addition to a large number of amorphous substances in sample A-2, there are characteristic diffraction peaks of $\mathrm{CaCO}_{3}\left(2 \mathrm{\theta}\right.$ are $29.3^{\circ}, 39.4^{\circ}, 43.1^{\circ}$, and $\left.47.4^{\circ}\right)$, which indicates that sample A-2 contains mineralized products.

\subsubsection{FTIR characterization}

Figure 10 shows the FTIR spectra of mineralized products, samples R and A-2. Figure 10 shows the FTIR spectra of mineralized products, samples $R$ and $A-2$. In sample $R, 797.69 \mathrm{~cm}^{-1}$ is the stretching vibration peak of $-\mathrm{CH}$ outside the aromatic ring. At $1031.46 \mathrm{~cm}^{-1}$ is the stretching vibration peak of minerals such as quartz and kaolinite. The stretching vibration peaks of $-\mathrm{CH}_{2}$ and $-\mathrm{CH}_{3}$ are at 2862.23 and 2915.95 $\mathrm{cm}^{-1}$, respectively. The stretching vibration peak of $-\mathrm{OH}$ is at $3438.75 \mathrm{~cm}^{-1}$. In the mineralized product samples, at 1416.80 and $872.81 \mathrm{~cm}^{-1}$ are the antisymmetric and symmetrical stretching vibration peaks of the $\mathrm{C}-\mathrm{O}$ bond in $\mathrm{CaCO}_{3}$, respectively. In sample A-2, the antisymmetric and symmetric stretching vibration peaks of the $\mathrm{C}-\mathrm{O}$ bond in $\mathrm{CaCO}_{3}$ are at 1405.99 and $871.70 \mathrm{~cm}^{-1}$, respectively. The reason for this difference is that the $-\mathrm{OH}$ bond in the coal dust and the $\mathrm{C}-\mathrm{O}$ bond in the mineralized product form an intermolecular hydrogen bond $\mathrm{O}-\mathrm{H} \cdots \mathrm{O}$, which makes the density of electron cloud between $\mathrm{C}-\mathrm{O}$ move towards $\mathrm{O}$ atom, resulting in the decrease of electron cloud density and the weakening of vibration force. Therefore, the antisymmetric stretching vibration peak and the symmetric stretching vibration peak move to the low-frequency direction (Rong et al., 2015). In the same way, the $-\mathrm{CH}\left(776.85 \mathrm{~cm}^{-1}\right)$ and $-\mathrm{OH}$ $\left(3440.35 \mathrm{~cm}^{-1}\right)$ groups in sample A-2 also shifted. From the above analysis, it can be seen that the mineralization product can consolidate coal dust because the intermolecular hydrogen bond is formed between the coal dust and the mineralization product.

\subsection{Molecular dynamics simulation}

\subsubsection{Distribution of water molecules in the system}

The initial state and the equilibrium state of the APG-water-coal system are shown in Figure 11. It can be observed from the figure that the water molecules are stratified with coal molecules in the initial state, and the water molecules move to the coal surface and interact with it in the equilibrium state. It can be seen from the equilibrium configuration that surfactant molecules cover the surface of coal seam. This is 
because the surface of coal molecules contains a large number of oxygen-containing groups, which makes it have a strong affinity with the hydrophilic groups of the surfactant. When Van der Waals force, Coulomb force, and solid-liquid surface tension reach equilibrium, the droplet will no longer spread. As the molecular weight of the surfactant increases, more surfactant molecules are adsorbed on the surface of coal molecules, and more water molecules enter the interstices of coal molecules, which indicates that the degree of diffusion of water molecules on the coal surface becomes stronger.

\subsubsection{Relative concentration distribution}

Figure 12 shows the relative concentration distribution of the APG-water-coal system along the Z-axis perpendicular to the coal surface. The relative concentration distribution peaks of different substances represent the locations where the molecules are more concentrated (Meng et al., 2019). It can be seen from Figure 12 that the relative concentration distribution of coal is not affected by the number of water molecules and APG molecular chains. The overlapping part of the concentration distribution of surfactant or water molecule and coal indicates that the surfactant or water penetrates into the coal, which to some extent indicates the wetting effect of water on the coal. When the surfactant is added, the location of the surfactant is closer to coal than water. This is because the hydrophobic group in the surfactant is in contact with coal, and the hydrophilic group is in contact with water. The surfactant acts as an "insulation layer" between water and coal and connects water and coal powder together. When the amount of surfactant added is different, the positions of surfactant appearing at 44.359, 39.288,38.529, and $47.551 \AA$, respectively (Figure 12b-d). As the amount of surfactant increases, the more "forward" it appears, which means that the surfactant is more permeable in coal. Although the surfactant dose added in Figure 12e is the largest, its appearance is "behind" than System II-IV. This shows that when the added amount of surfactant exceeds a certain concentration, the wettability of the system cannot play a positive role.

\subsubsection{Interaction energy between surfactant and coal dust}

The interaction energy in the APG-water-coal system is calculated using the following formula (Meng et al., 2019).

$\left.E_{\text {totar }}=E_{\text {total (APG-water-coal) }} E_{\text {total (APG) }} E_{\text {total (water) }}\right)^{-}$total (coal) $₫ 5 \rrbracket$

$E_{V D W}=E_{V D W(A P G \text {-water-coal) }} E_{V D W(A P G)} E_{V D W(\text { water }}{ }^{-} E_{V D W(\text { coal) }}$ \$6ه

$\left.E_{L}=E_{L(A P G \text {-water-coal) }} E_{L(A P G)} E_{L(\text { water }}\right)^{-E_{L}(\text { coal) }}$

87区

Among them, $E_{\text {total }}$ is the total energy of the APG-water-coal system, $\mathrm{kcal} / \mathrm{mol} ; E_{V D W}$ is the van der Waals energy, $\mathrm{kcal} / \mathrm{mol} ; E_{L}$ is the electrostatic interaction energy, $\mathrm{kcal} / \mathrm{mol}$.

From the energy point of view, the more negative the Etotal, the more favorable the adsorption of the surfactant APG with coal. The total energy of the system, van der Waals interaction energy and 
electrostatic interaction energy are shown in Table 4. It can be seen from Table 4 that the system (I) without surfactant molecules has the largest interaction energy, which indicates that the adsorption stability between pure water and coal is poor. As the number of surfactant molecules increases, the interaction energy between coal molecules and surfactant molecules increases gradually. and the system becomes increasingly stable. In addition, the results of this study are consistent with the study of Vatanparast et al. (2018), that is, as the number of surfactant molecules increases, the proportion of van der Waals action energy gradually decreases, while the proportion of electrostatic action energy gradually increases. In all the systems, the proportion of electrostatic interaction is very high, indicating that electrostatic interaction plays a dominant role in the adsorption process (Rai et al., 2011).

\subsection{SEM-EDS characterization}

Figure 13a-j shows the microscopic morphology of different samples. It can be seen from Figure 13a that the mineralized product is spherical and has a smooth surface. Figure 13b shows the microscopic morphology of coal powder. Its shape is irregular, there is no connection between the coal particles, and they are loosely piled together. Figure $13 \mathrm{c}$ is a sample sprayed with APG and urea- $\mathrm{CaCl}_{2}$ solution, and its morphology is almost the same as Figure 13b.It can be seen in Figure 13d, $f$ and $i$ that there are no obvious gaps between the coal dust particles, almost becoming a whole, and the surface of the coal dust is relatively rough compared to Figure $13 \mathrm{~b}$. The reason for this phenomenon is presumed to be that the mineralized product wraps the coal powder during the crystallization process, and then connects the coal particles together. At the same time, spherical mineralization products were also found in these samples. Further observation in Figure 13e, $\mathrm{h}$ and $\mathrm{j}$, it can be found that there are still larger gaps between the coal dust at the bottom of Figure 13e, and most of the coal dust particles have flat surfaces. In the coal dust at the bottom of Figure 13h, the surface of coal dust is rough, and the gap between coal dust particles is small, and there is a tendency to connect as a whole, which is consistent with the phenomenon observed in the anti-wind erosion test. The difference between the bottom and the surface of the coal dust in Figure $13 i$ and $j$ is small, and both can be consolidated. Spherical mineralization products are also observed in the coal dust in Figure 13j. The reason for the difference in the samples selected at the bottom of the coal dust in Figure 13e, $\mathrm{h}$, and $\mathrm{j}$ is that the concentration of APG added is different. When the APG concentration is small, the coal dust is not easy to wet, and the urea- $\mathrm{CaCl}_{2}$ and urease solutions are difficult to penetrate into the coal dust, resulting in limited consolidation of the coaldust at the bottom. As the concentration of APG increases, the wettability of the solution increases, and the solution of urea$\mathrm{CaCl}_{2}$ and urease penetrates into the coal dust, consolidating the coal dust particles together.

Figure 13k and I show the EDS analysis at the mark in Figure 13g. It can be seen from the figure that the coal dust contains elements such as $\mathrm{C}, \mathrm{O}, \mathrm{N}, \mathrm{S}, \mathrm{Si}$, and $\mathrm{Al}$, and the agglomerated spherical material contains $\mathrm{C}, \mathrm{O}$, and $\mathrm{Ca}$. It can be seen from the mass ratio of the three elements that the substance is $\mathrm{CaCO}_{3}$. At the same time, from the changes in the microscopic morphology of the bottom sample of the coal dust in Figure 13e, $h$, and $\mathrm{j}$, it can be inferred that the consolidation process of the biological dust suppressant on the coal dust is as follows. The mineralization product $\mathrm{CaCO}_{3}$ first appeared on the 
surface of the coal dust and gradually wrapped the coal dust. With the further precipitation of $\mathrm{CaCO}_{3}$, the coal dust particles were connected together to form a consolidated body, thereby achieving the purpose of dust retention.

In summary, the consolidation process of coal dust by biological dust suppressants is divided into the following two steps: ( $\mathbb{(})$ The hydrophobic group in the surfactant (APG) combines with the hydrophobic group in the coal dust to form a distribution of hydrophobic groups facing inward and hydrophilic groups facing outward, thereby improving the wettability of coal dust (Figure 14a). At this time, the urea, $\mathrm{Ca}^{2+}$ and urease in the biological dust suppressant solution can enter the coal dust and be distributed in the pores between the coal dust (Figure $14 \mathrm{~b}$ ). ( () Urease in coal dust pore decomposes urea into $\mathrm{CO}_{3}{ }^{2-}, \mathrm{CO}_{3}{ }^{2-}$ reacts with $\mathrm{Ca}^{2+}$ to produce $\mathrm{CaCO}_{3}$, in which $\mathrm{C}-\mathrm{O}$ bond forms intermolecular hydrogen bond $\mathrm{O}-\mathrm{H} \cdots \mathrm{O}$ with $-\mathrm{OH}$ in coal dust. With the increase of $\mathrm{CaCO}_{3}$, coal dust particles are consolidated into a whole (Figure 14c).

\subsection{Environmental protection of biological dust suppressant}

Urease, urea, $\mathrm{CaCl}_{2}$ and $\mathrm{APG}$ are the main components of dust suppressant in this study. Urease is essentially a protein, urea is easy to decompose, $\mathrm{CaCl}_{2}$ is an inorganic salt, APG is essentially a degradable polysaccharide, and the above substances will hardly have a bad impact on the ecological environment. In addition, its mineralization product $\mathrm{CaCO}_{3}$ is a widely existing substance in nature. Through previous research (Wu et al., 2020), it was found that the highest pH value of the dust suppressant during the mineralization process was 8.04 , and after the reaction was stable at about 7.86 , which was non-toxic. This shows that the prepared dust suppressant is neutral and is an environmentally friendly dust suppressant.

\section{Conclusion}

In this paper, a biological dust suppressant was prepared based on the synergistic effect of surfactant and enzyme-induced carbonate precipitation. The best type and dosage of surfactants in biological dust suppressants, the dust-fixing effect and dust-fixing mechanism of biological dust suppressants are determined. The APG has the least effect on urease activity among the CTAB, SDS, SDBS and APG, and the urease activity is close to $25 \mathrm{mmol} / \mathrm{L}$. The contact angle and sedimentation rate tests show that when the surfactant concentration exceeds $0.2 \%$, the wetting effect of the biological dust suppressant is more obvious. Finally, a non-ionic surfactant APG with a concentration of $0.3 \%$ was selected to prepare dust suppressant. The optimal proportion of biological dust suppressant was: the concentration of urea-cacl2 was $0.6 \mathrm{~mol} / \mathrm{l}$, the ratio of urease (produced by soybean) to urea- $\mathrm{CaCl}_{2}$ was $1: 3(\mathrm{~V} / \mathrm{V}), \mathrm{APG}$ was $0.3 \%$ $(\mathrm{V} / \mathrm{V})$. The wind erosion resistance of the sample after treatment with biological dust suppressant was increased by $86.69 \%$. Evaporation resistance shows that the biological dust suppressant has good water retention. Research on dust-fixation mechanism shows that the adsorption of biological dust suppressant and coal dust is mainly due to the electrostatic force between the surfactant and coal powder. The 
mineralization product is calcite-type calcium carbonate. The mineralized product after the reaction first adheres to the surface of coal dust, and part of the product fills the pores of coal dust. With the increase of mineralization products, calcium carbonate adheres to the coal dust particles and gradually wraps the coal dust, thereby consolidating the coal dust into a whole. The mineralization product can consolidate coal powder because it forms intermolecular hydrogen bonds with coal dust. The synergistic effect of surfactant and urease in inducing carbonate precipitation is embodied in the fact that the surfactant wets the coal dust so that urease and urea- $\mathrm{CaCl}_{2}$ can enter the inside of the coal powder, and then the urease mineralizes the $\mathrm{CaCO}_{3}$ to consolidate the coal powder into a whole. And the biological dust suppressant is an environmentally friendly dust suppressant.

\section{Declarations}

\section{Ethics approval and consent to participate}

Not applicable.

\section{Consent for publication}

Not applicable.

\section{Availability of data and materials}

All data generated or analysed during this study are included in this paper.

\section{Competing interests}

The authors declare no conflict of interest.

\section{Funding Information}

This work was supported by the National Key R\&D Program of China [grant number 2018YFC0807900]; the National Natural Science Foundation of China [grant numbers 51674038, 51874193, 42077444]; the Shandong Province Natural Science Foundation [grant number ZR2018JL019, ZR2020ME101]; the State Key Program for Coal Joint Funds of the National Natural Science Foundation of China [grant number U1261205]; Scientific Research Foundation of Shandong University of Science and Technology for Recruited Talents [grant numbers 2017RCJJ010, 2017RCJJ037]; Shandong Province First Class Subject Funding Project [grant number 01AQ05202].

\section{Authors' contributions}

Conceptualization: Xiangming Hu, Yanyun Zhao; methodology: Mingyue Wu; software: Qian Zhang; data curation: Mingyue Wu, Di Xue; writing original draft preparation: Mingyue Wu, Qian Zhang; visualization: Mingyue Wu; supervision: Xiangming Hu, Yanyun Zhao, Weimin Cheng; funding acquisition: Xiangming $\mathrm{Hu}$, Yanyun Zhao, Weimin Cheng. 
Acknowledgements

Not applicable.

\section{References}

Ayoglu FN, Acikgoz B, Tutkun E, et al. (2014). Descriptive Characteristics of Coal Workers' Pneumoconiosis Cases in Turkey. Iran J Public Health 43(3), 389-390.

Bao Q, Nie W, Liu CQ, et al. (2020). The preparation of a novel hydrogel based on crosslinked polymers for suppressing coal dusts. J Clean Prod 249, 119343. Doi: 10.1016/j.jclepro.2019.119343

Chang P, Chen Y, Xu G, et al. (2019). Numerical study of coal dust behaviours and experimental investigation on coal dust suppression efficiency of surfactant solution by using wind tunnel tests. Energy Source Part A 1-16. Doi:10.1080/15567036.2019.1639855

Chen Y, Xu G, Huang J, et al. (2019). Characterization of coal particles wettability in surfactant solution by using four laboratory static tests. Colloid Surface A 567, 304-312. Doi: 10.1016/j.colsurfa.2019.01.068

Cui D, Baisheng N, Hua Y, et al. (2011). Experimental Research on Optimization and Coal Dust Suppression Performance of Magnetized Surfactant Solution. Procedia Eng 26, 1314-1321. Doi: 10.1016/j.proeng.2011.11.2306

Cybulski K, Malich B, Wieczorek A. (2015). Evaluation of the effectiveness of coal and mine dust wetting. J Sustain Min 14(2), 83-92. Doi: 10.1016/j.jsm.2015.08.012

Dang XG, Shan ZH, Chen H. (2017). Usability of oxidized corn starch-gelatin blends for suppression and prevention of dust. J Appl Polym Sci 134(6), APP.44437. Doi: 10.1002/app.44437

Dixon-Hardy DW, Beyhan S, Ediz IG, et al. (2008). The Use of Oil Refinery Wastes as a Dust Suppression Surfactant for Use in Mining. Environ Eng Sci 25(8), 1189-1196. Doi:10.1089/ees.2007.0177

Fu SK, Ma Z, Peng JC (2021). "Political blue sky" in fog and haze governance: evidence from the local major international events in China. Environ Sci Pollut Research 28(1) 775-788. Doi: 10.1007/s11356020-10483-y

Fan T, Zhou G, Wang J (2018). Preparation and characterization of a wetting-agglomeration-based hybrid coal dust suppressant. Process Saf Environ Prot 113, 282-291. Doi: 10.1016/j.psep.2017.10.023

Guo J, Zhang L, Liu S, et al. (2018). Effects of hydrophilic groups of nonionic surfactants on the wettability of lignite surface: Molecular dynamics simulation and experimental study. Fuel 231, 449-457. Doi: 10.1016/j.fuel.2018.05.106 
Hamdan N, Kavazanjian E (2016). Enzyme-induced carbonate mineral precipitationfor fugitive dust control. Geotech 66, 546-555.

Kavazanjian E, Almajed A, Hamdan N (2017). Bio-Inspired Soil Improvement Using EICP Soil Columns and Soil Nails. Geotech Spec Pub 288: 13-22.

Krajewska B (2018). Urease-aided calcium carbonate mineralization for engineering applications: A review. J Adv Research, 13, 59-67. Doi: 10.1016/j.jare.2017.10.009

Medeiros MA, Leite CMM, Lago RM (2012). Use of glycerol by-product of biodiesel to produce an efficient dust suppressant. Chem Eng J 180, 364-369. Doi: 10.1016/j.cej.2011.11.056

Meng J, Yin F, Li S, et al. (2019) Effect of different concentrations of surfactant on the wettability of coal by molecular dynamics simulation. Int J.Min Sci Technol 29, 577-584.

Musselman SW, Chander S (2002). Wetting and adsorption of acetylenic diol based nonionic surfactants on heterogeneous surfaces. Colloid Surfaces A 206(1), 497-513. Doi: 10.1016/S0927-7757(02)00055-9

Northey SA, Mudd GM, Saarivuori E, et al. (2016). Water foot printing and mining: Where are the limitations and opportunities? J Clean Prod 135, 1098-1116. Doi: 10.1016/j.jclepro.2016.07.024

Pollock DE, Potts J, Joy G (2010). Investigation into dust exposures and mining practices in mines in the southern Appalachian Region. Min Eng 62: 44-49.

Rai B, Sathish P, Tanwar J, et al. (2011). A molecular dynamics study of the interaction of oleate and dodecylammonium chloride surfactants with complex aluminosilicate minerals. J Colloid and Interf Sci 362(2), 510-516. Doi: 10.1016/j.jcis.2011.06.069

Rong H, Qian C 2015. Binding functions of microbe cement. Adv Eng Mater 17(3), 334-340. Doi: 10.1002/adem. 201400030

Song JY, Sim Y, Jang J, et al. (2019). Near-surface soil stabilization by enzyme-induced carbonate precipitation for fugitive dust suppression. Acta Geotech 15(7), 1967-1980. Doi:10.1007/s11440-019$00881-z$

Vatanparast $H$, Shahabi F, Bahramian A, et al. (2018). The Role of Electrostatic Repulsion on Increasing Surface Activity of Anionic Surfactants in the Presence of Hydrophilic Silica Nanoparticles. Sci Rep 8(1), 7251. Doi: 10.1038/s41598-018-25493-7

Wang J, Zhou G, Wei X, et al. (2019). Experimental characterization of multi-nozzle atomization interference for dust reduction between hydraulic supports at a fully mechanized coal mining face. Environ Sci Pollut Research 26(10), 10023-10036. Doi:10.1007/s11356-019-04413-w 
Wang YY, Zhou G, Xu CC, et al. (2020) Synthesis and characteristics of a novel dust suppressant with good weatherability for controlling dust in open coal yards. Environ Sci Pollut Research 27(16), 1932719339. Doi:10.1007/s11356-020-08309-y

Wu MY, Hu XM, Zhang Q, et al., (2020). Preparation and performance evaluation of environment-friendly biological dust suppressant. J Clean Prod 273: 123162. Doi: 10.1016/j.jclepro.2020.123162

Xiao YC, Zheng C, Gan MK, et al. (2015). The Preparation of CMC-PVA-AM Dust Suppression Agent and its Application Appraisement. Adv Mater Research 1120-1121, 628-634. Doi:

10.4028/www.scientific.net/AMR.1120-1121.628

Xu G, Chen Y, Eksteen J, et al. (2018). Surfactant-aided coal dust suppression: A review of evaluation methods and influencing factors. Sci Total Environ 639, 1060-1076. Doi: 10.1016/j.scitotenv.2018.05.182

Yao QG, Xu, CC, Zhang YS, et al. (2017). Micromechanism of coal dust wettability and its effect on the selection and development of dust suppressants. Process Saf Environ Prot 111, 726-732. Doi:

10.1016/j.psep.2017.08.037

Zhang KX, Zhang J, Wei JP, et al. (2019). Coal seam water infusion for dust control: a technical review. Environ Sci Pollut Research 26(5), 4537-4554. Doi:10.1007/s11356-018-04086-x

Zhang Q, Zhou G, Qian X, et al. (2018). Diffuse pollution characteristics of respirable dust in fullymechanized mining face under various velocities based on CFD investigation. J Clean Prod 184, 239-250. Doi: 10.1016/j.jclepro.2018.02.230

Zhou G, Qiu H, Zhang Q, et al. (2016). Experimental Investigation of Coal Dust Wettability Based on Surface Contact Angle. J Chem 2016, 1-8. Doi:10.1155/2016/9452303

\section{Tables}

Table 1 Spraying components and dosage in different coal samples

\begin{tabular}{|c|c|c|c|c|}
\hline Treatment & Water $(\mathrm{mL})$ & APG (\%) & Urea-CaCl $2(\mathrm{~mL})$ & Urease $(\mathrm{mL})$ \\
\hline $\mathrm{R}$ & 40 & 0.00 & 0 & 0 \\
\hline$A-0$ & 10 & 0.30 & 30 & 0 \\
\hline$A-1$ & 0 & 0.10 & 30 & 10 \\
\hline$A-2$ & 0 & 0.30 & 30 & 10 \\
\hline A-3 & 0 & 0.50 & 30 & 10 \\
\hline
\end{tabular}

Table 2 Spraying components and dosage in anti-evaporation samples 


\begin{tabular}{|lllll|}
\hline Treatment & Water $(\mathrm{mL})$ & APG $(\%)$ & Urea- $\mathrm{CaCl}_{2}(\mathrm{~mL})$ & Urease $(\mathrm{mL})$ \\
\hline $\mathrm{R}$ & 40 & 0.30 & 0 & 0 \\
\hline $\mathrm{S}$ & 10 & 0.30 & 30 & 0 \\
\hline $\mathrm{T}$ & 0 & 0.30 & 30 & 10 \\
\hline
\end{tabular}

Table 3 APG-water-coal simulation system

\begin{tabular}{|lllll|}
\hline Systems & $\begin{array}{l}\text { APG molecular } \\
\text { number }\end{array}$ & $\begin{array}{l}\mathrm{H}_{2} \mathrm{O} \text { molecular } \\
\text { number }\end{array}$ & $\begin{array}{l}\text { Coal molecular } \\
\text { number }\end{array}$ & $\begin{array}{l}\text { System size } \\
\left(\AA^{3}\right)\end{array}$ \\
\hline$\square$ & 0 & 1000 & 10 & $30 \times 30 \times 141.485$ \\
\hline$\square$ & 5 & 1000 & 10 & $30 \times 30 \times 146.844$ \\
\hline$\square$ & 10 & 1000 & 10 & $30 \times 30 \times 153.767$ \\
\hline$\square$ & 20 & 1000 & 10 & $30 \times 30 \times 160.828$ \\
\hline$\square$ & 30 & 1000 & 10 & $30 \times 30 \times 166.855$ \\
\hline
\end{tabular}

Table 4 Interface interaction energy in different simulation systems

\begin{tabular}{|llllll|}
\hline Systems & $E_{\text {total }}(\mathrm{kcal} / \mathrm{mol})$ & $E_{V D W}(\mathrm{kcal} / \mathrm{mol})$ & $E_{V D W} / E_{\text {total }}(\%)$ & $E_{L}(\mathrm{kcal} / \mathrm{mol})$ & $E_{L} / E_{\text {total }}(\%)$ \\
\hline$\square$ & -406.216 & -121.98 & 30.028 & -226.437 & 55.743 \\
\hline$\square$ & -470.914 & -126.006 & 26.758 & -284.619 & 60.440 \\
\hline$\square$ & -749.958 & -124.717 & 16.630 & -561.611 & 74.886 \\
\hline$\square$ & -1432.016 & -325.377 & 22.722 & -1020.029 & 71.230 \\
\hline$\square$ & -1499.333 & -190.681 & 12.718 & -1223.906 & 81.630 \\
\hline
\end{tabular}

\section{Figures}




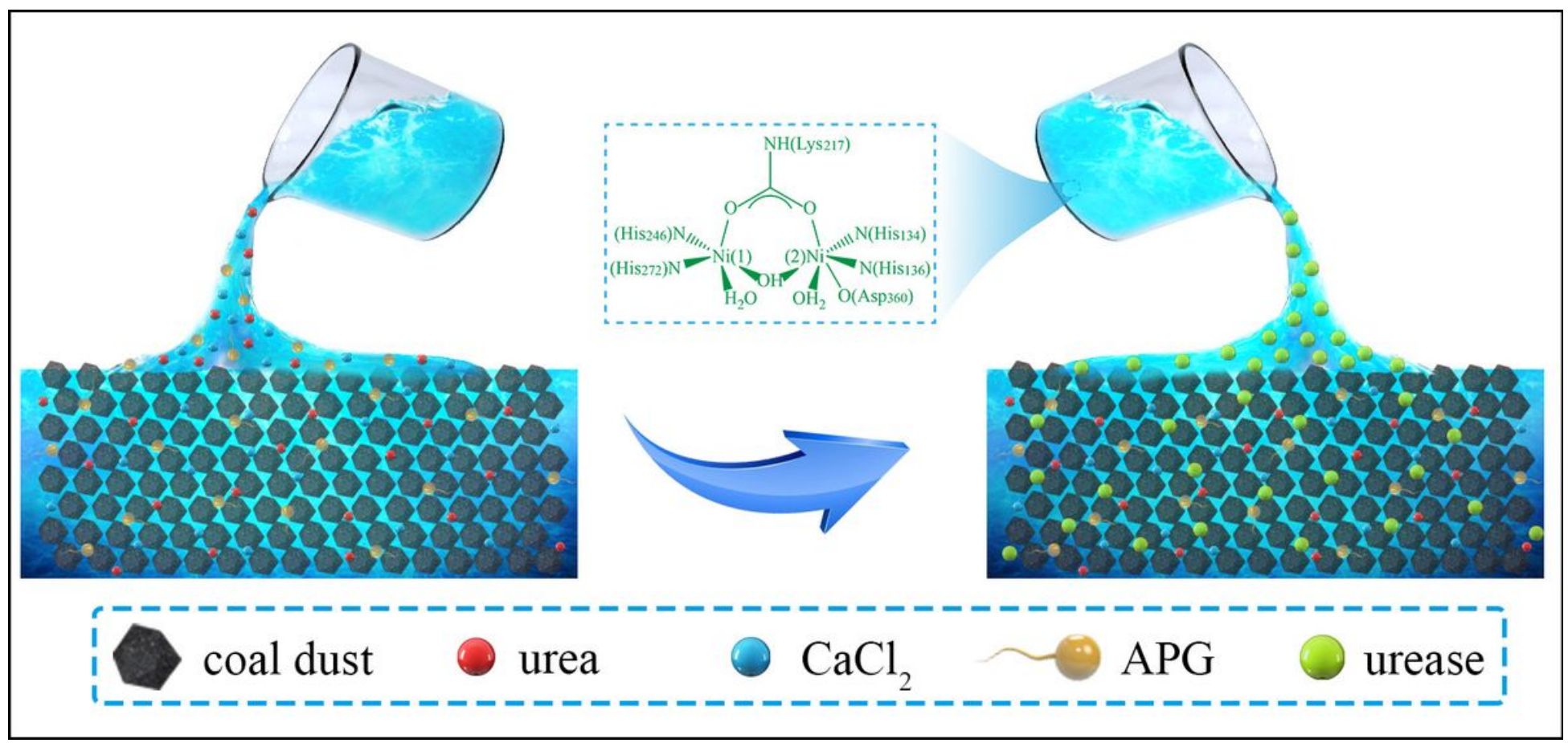

Figure 1

Application process of biological dust suppressant 


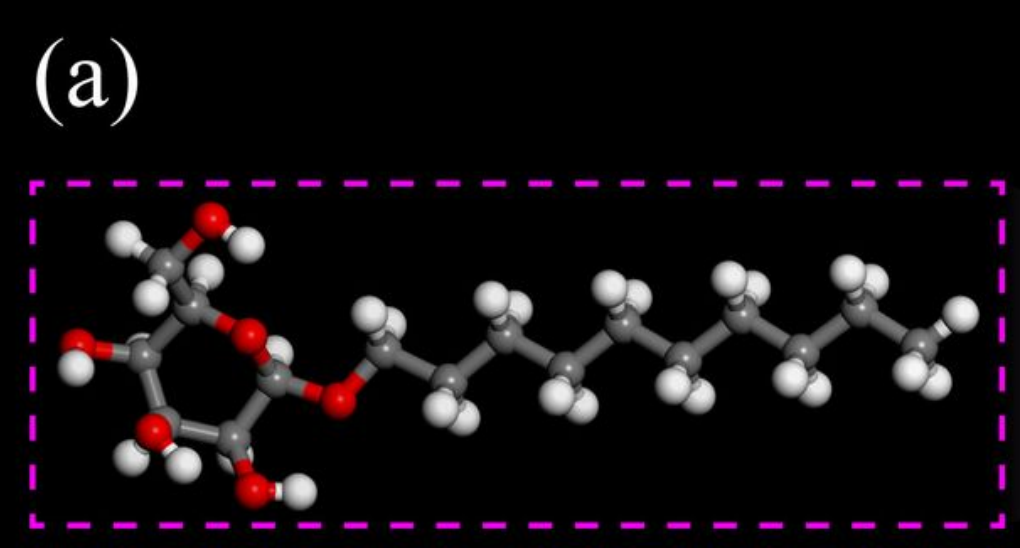

(b)
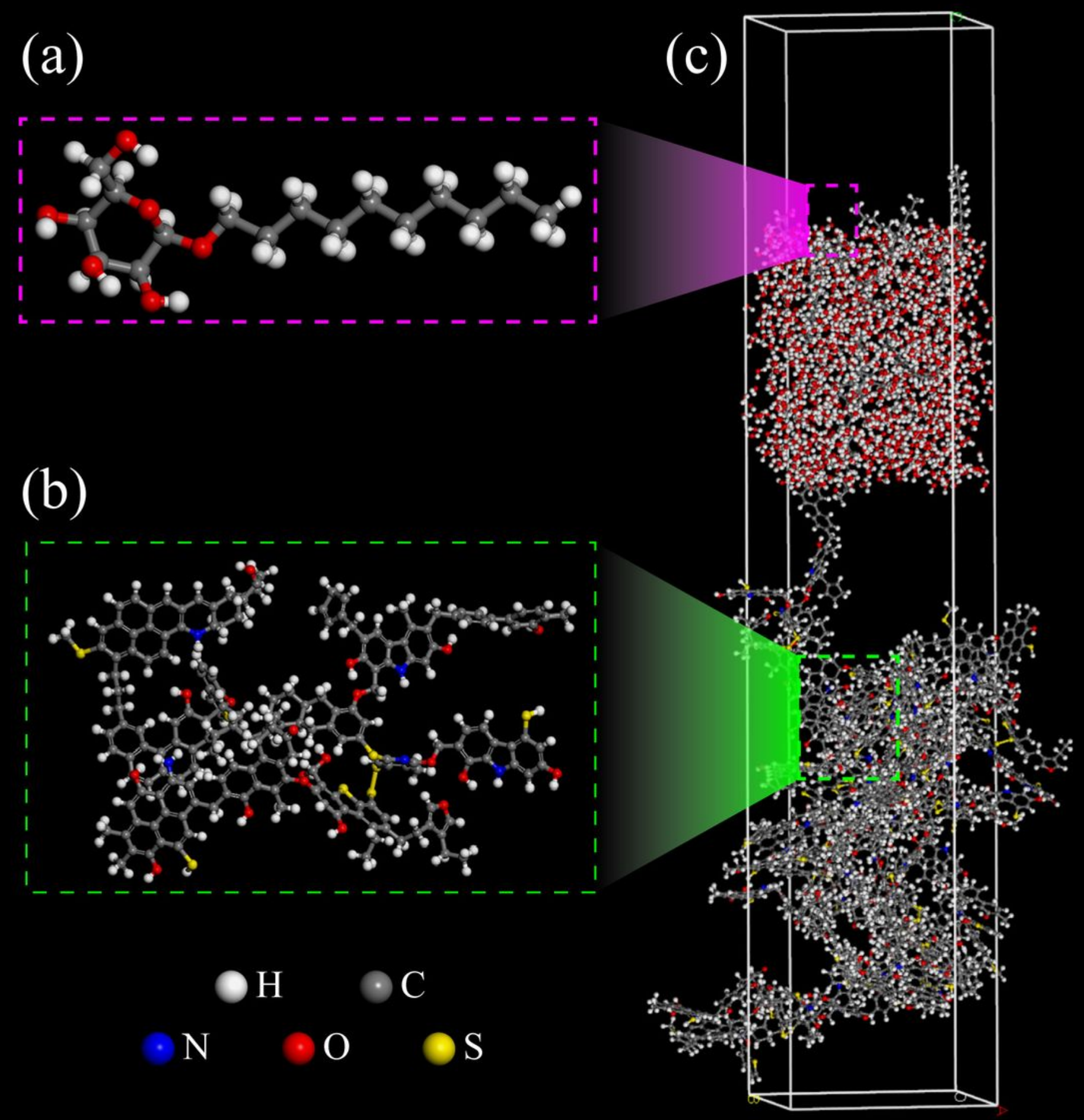

\section{Figure 2}

Molecular model ((a) Molecular structure model of APG; (b) Molecular structure model; (c) APG-water-coal simulation system) 


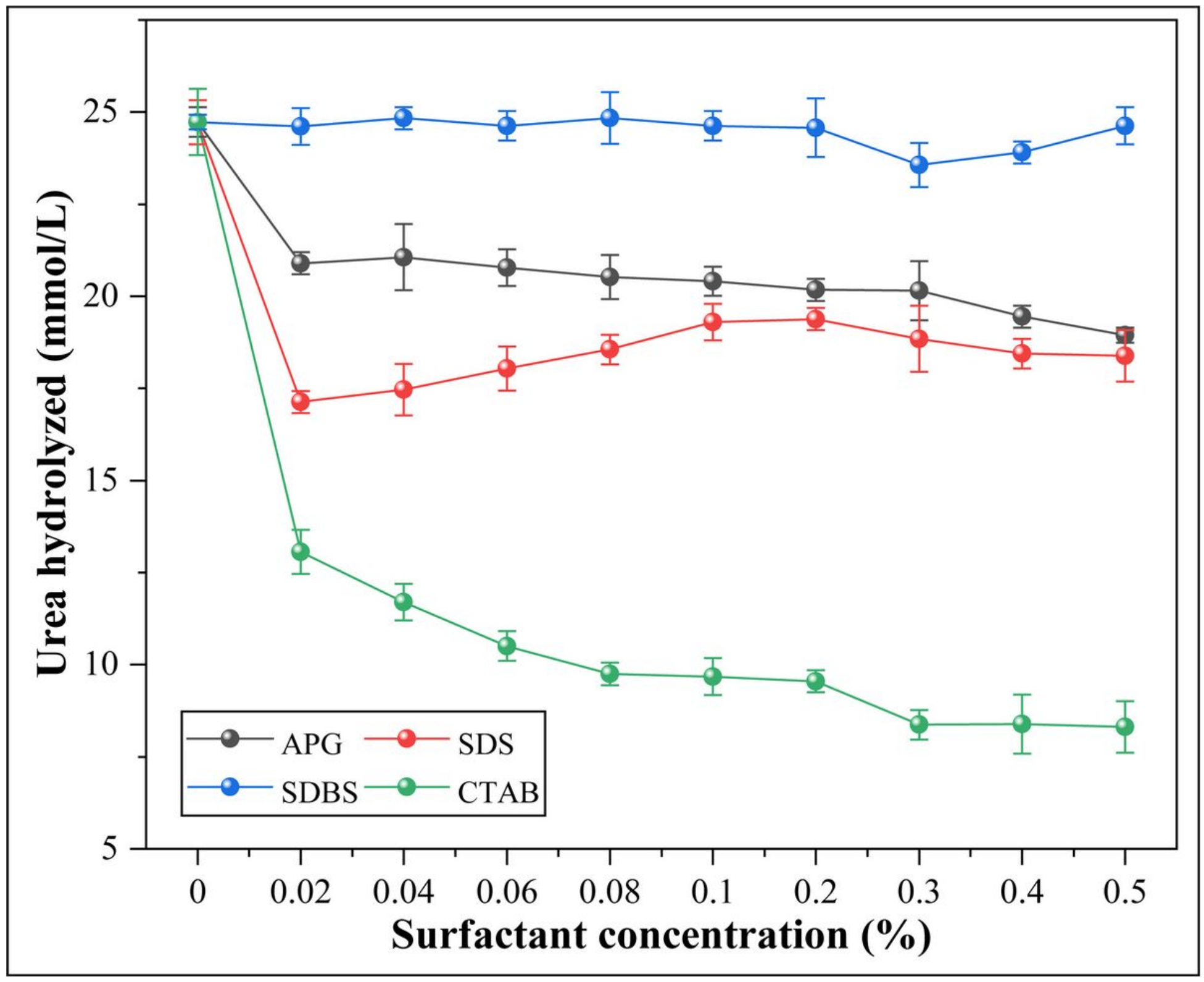

Figure 3

Effect of different surfactants on enzyme activity 

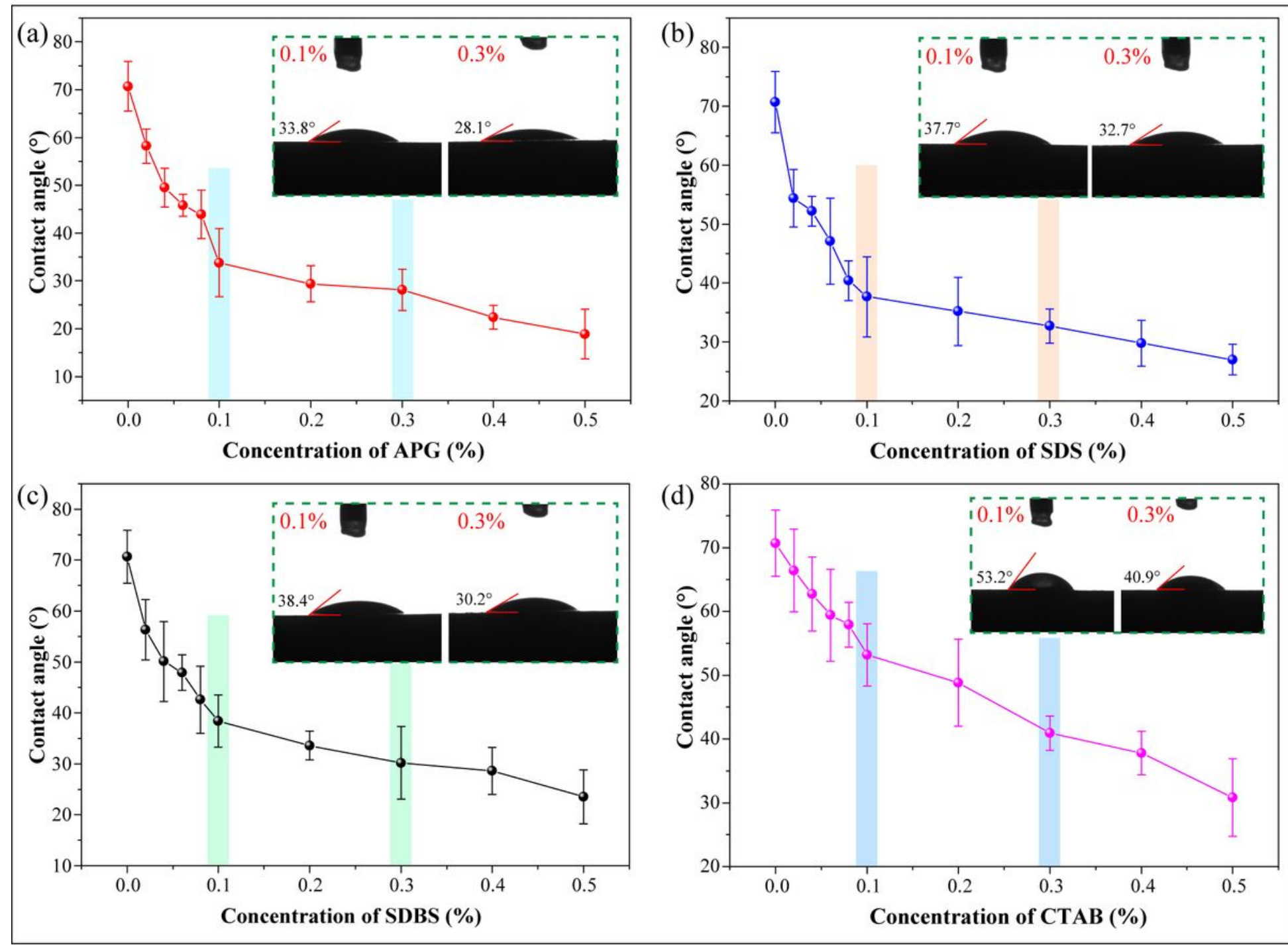

Figure 4

Contact angle of different surfactants (a. APG; b. SDS; c. SDBS; d. CTAB) 


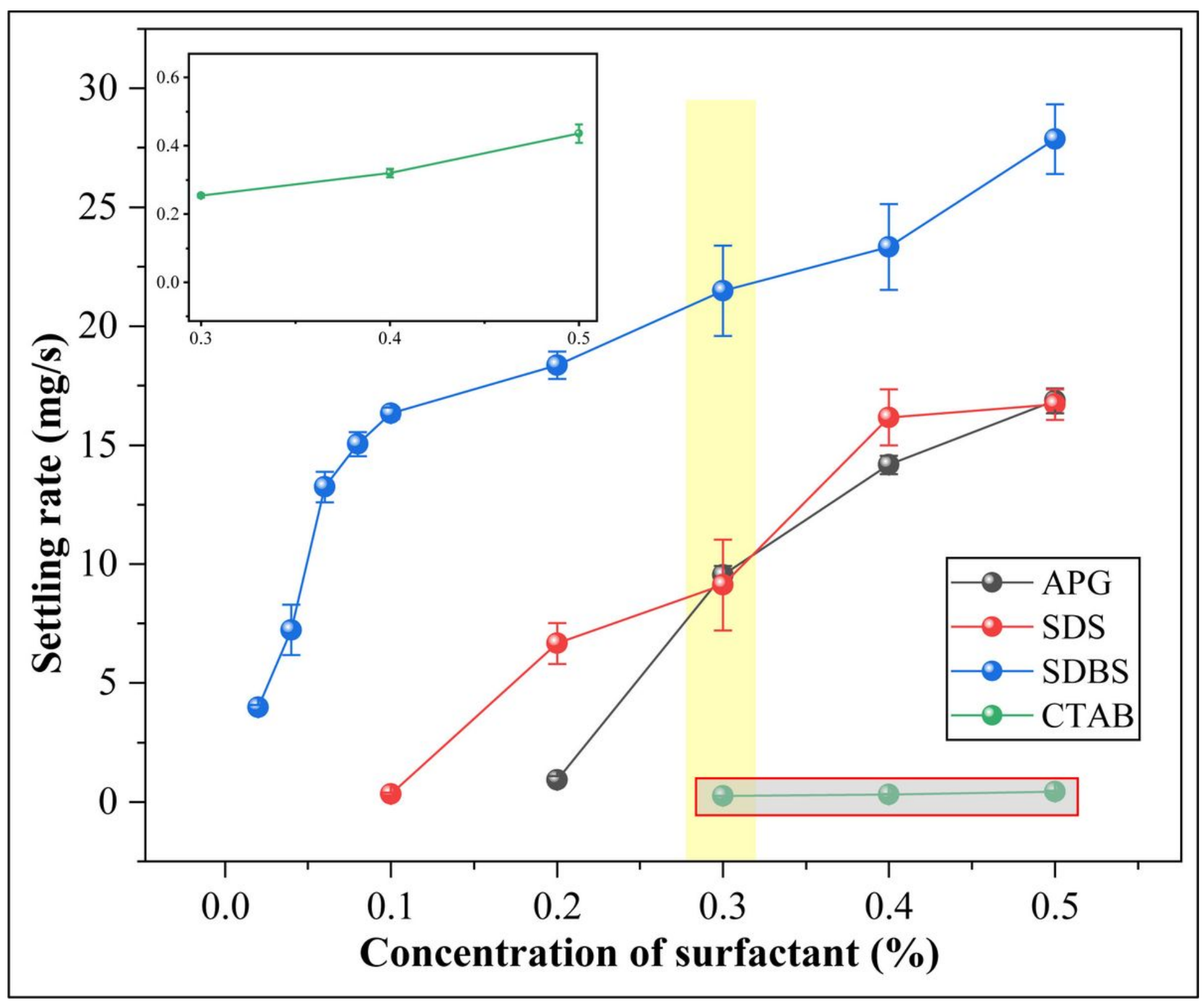

Figure 5

Settling rate of coal powder in different surfactants 

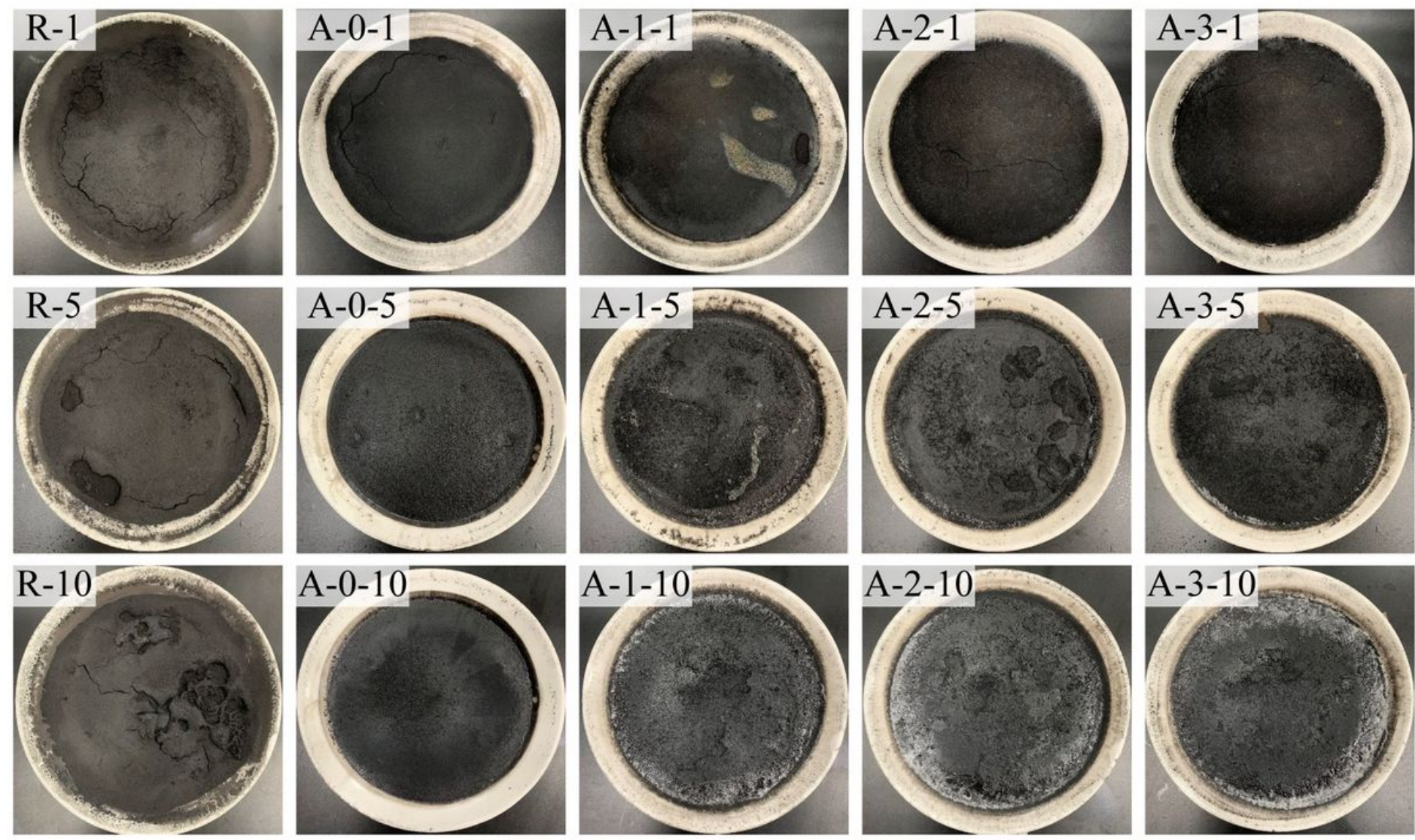

Figure 6

The surface morphology of coal powder after spraying different times 


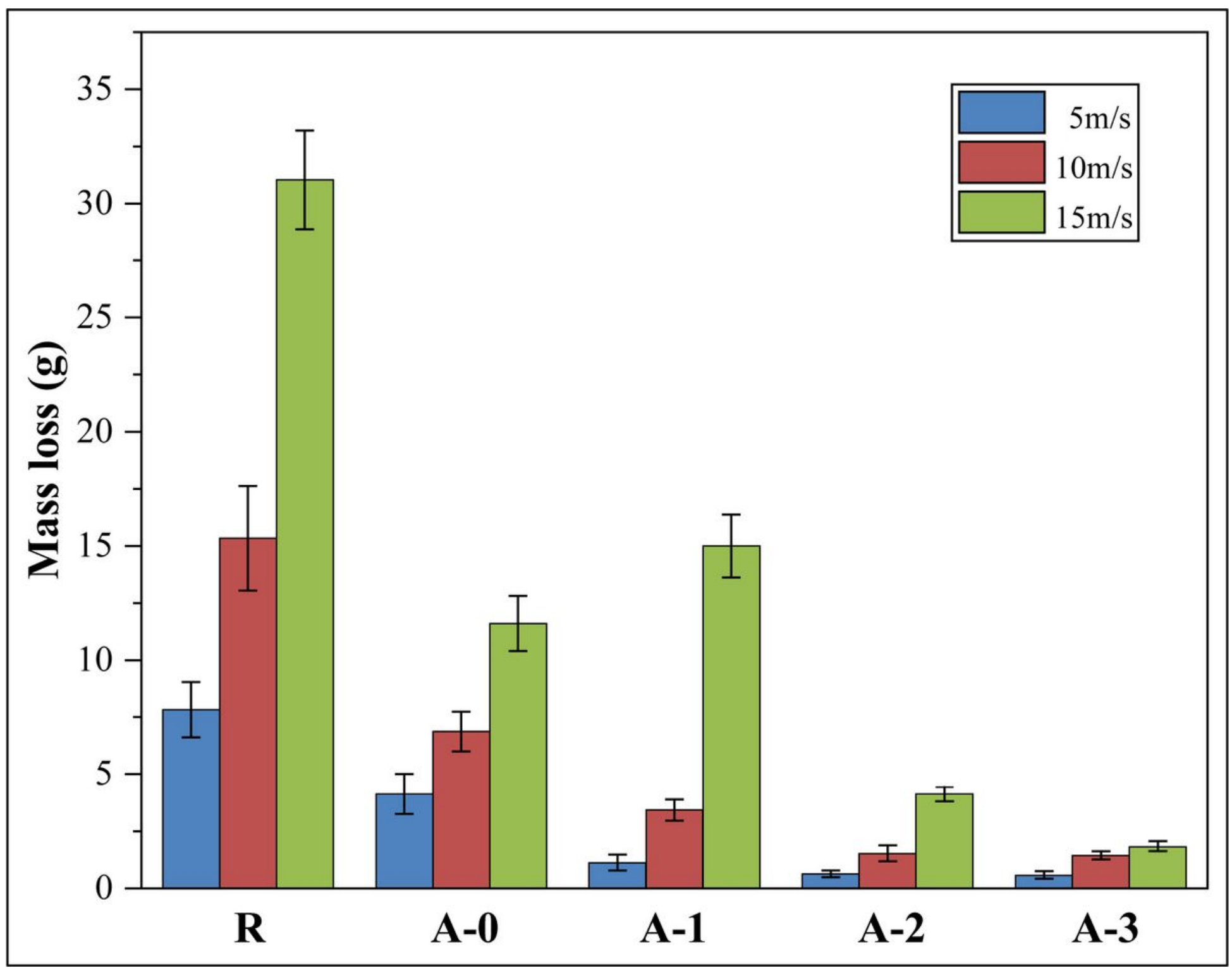

Figure 7

Mass loss at different wind speeds 


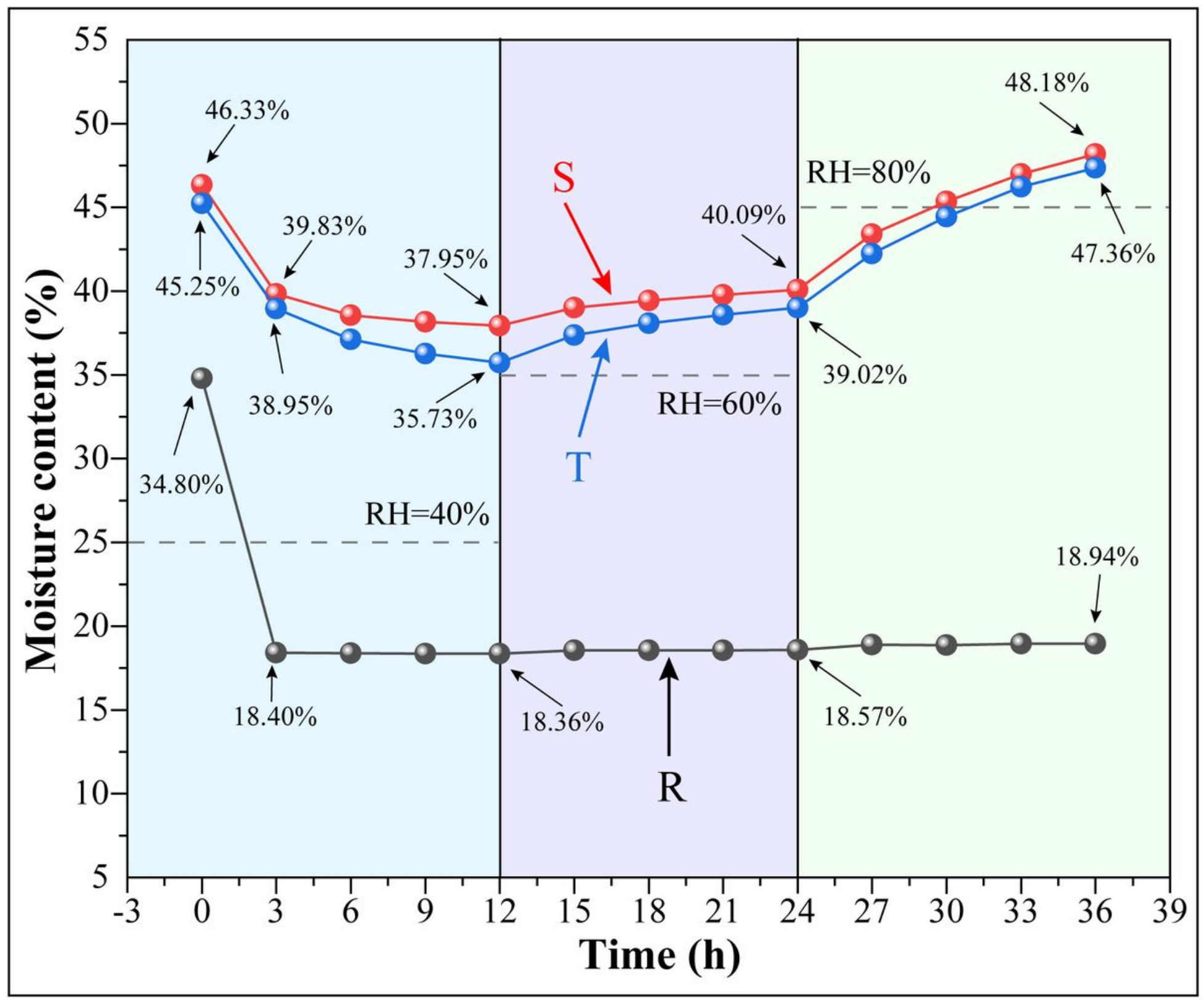

Figure 8

Resistance to evaporation of different samples 


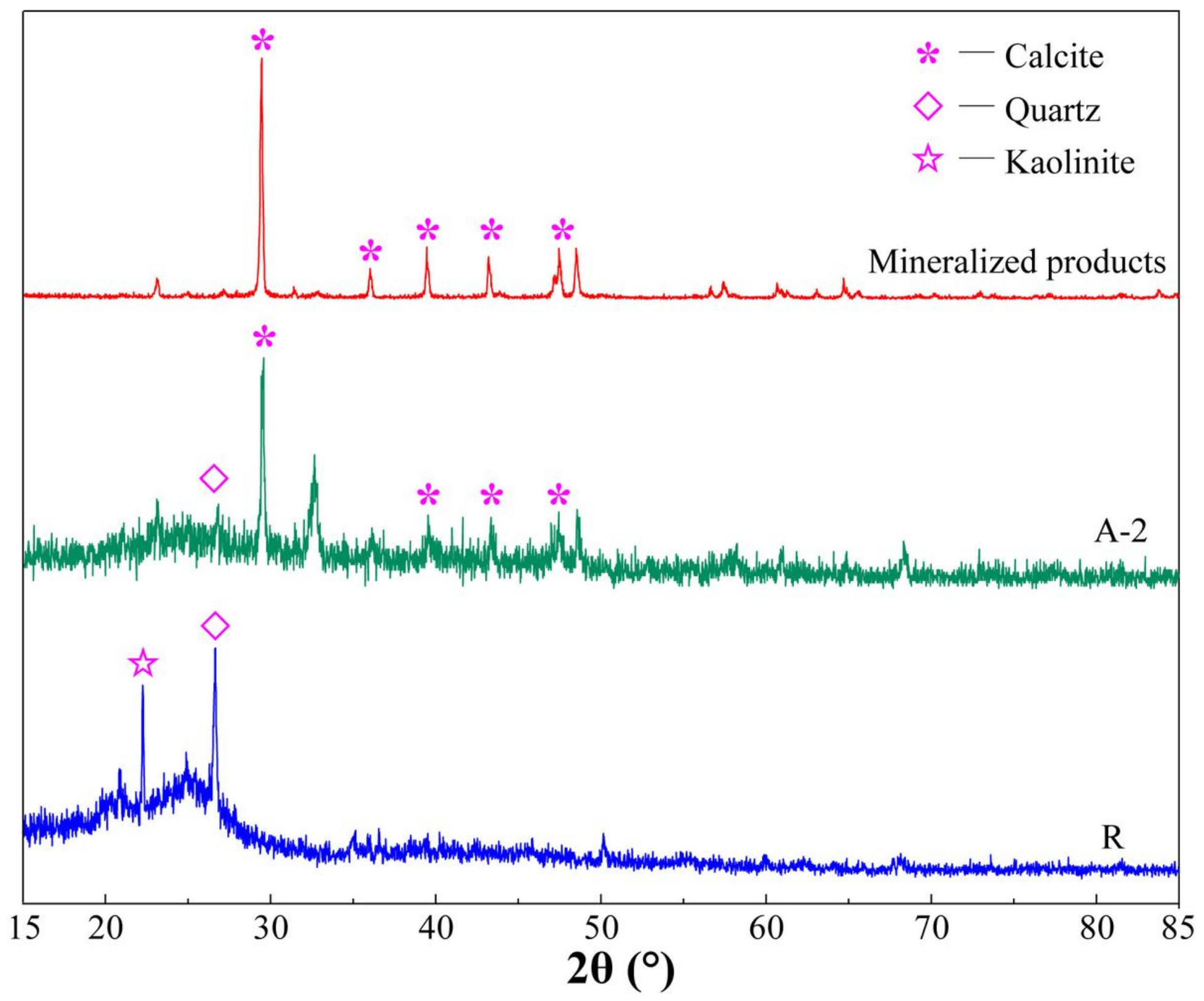

Figure 9

XRD patterns of different samples 


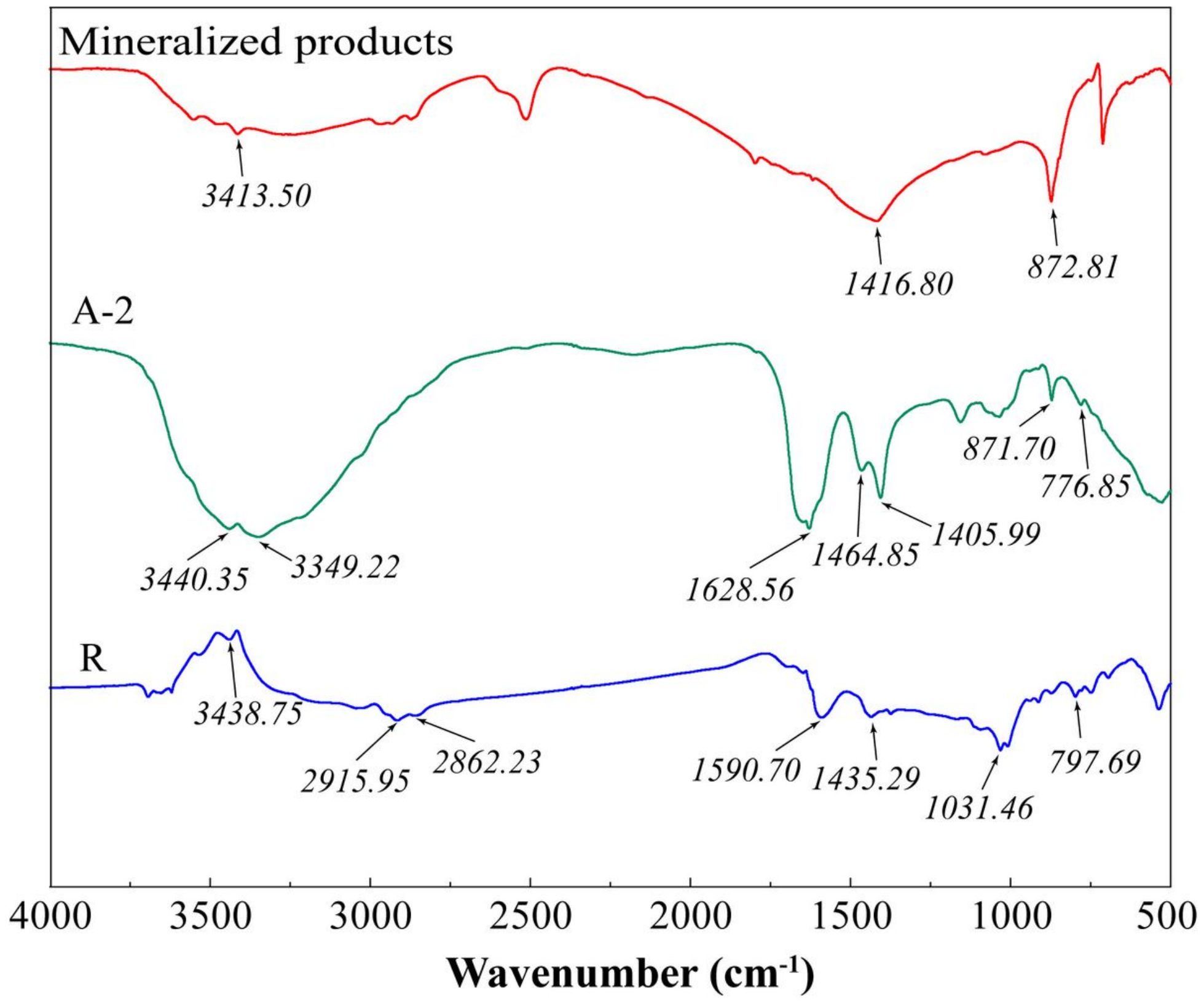

Figure 10

FTIR spectra of different samples 


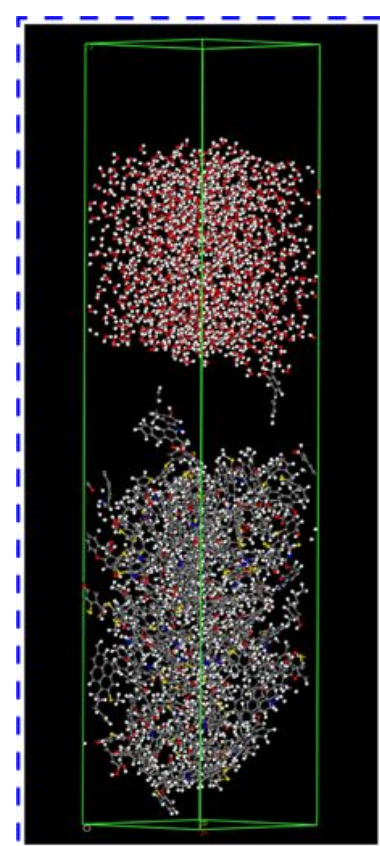

Initial state

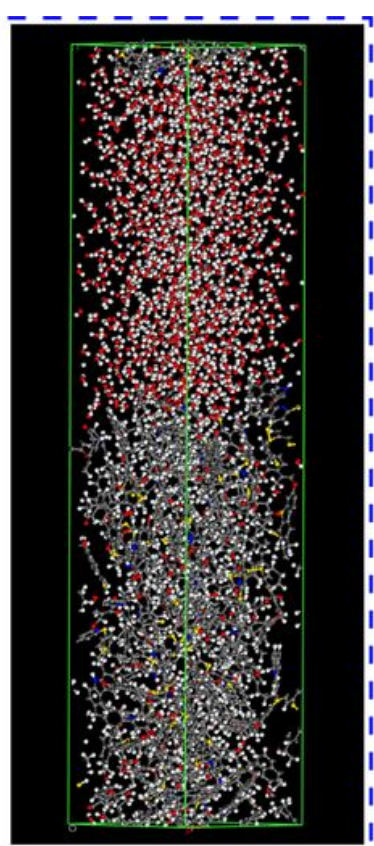

Final state

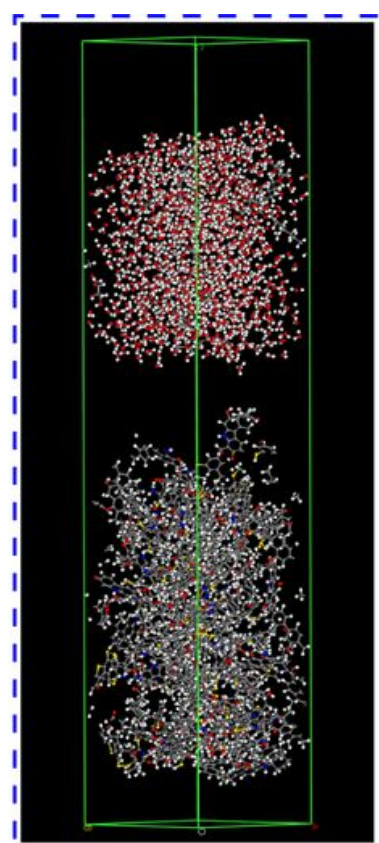

Initial state

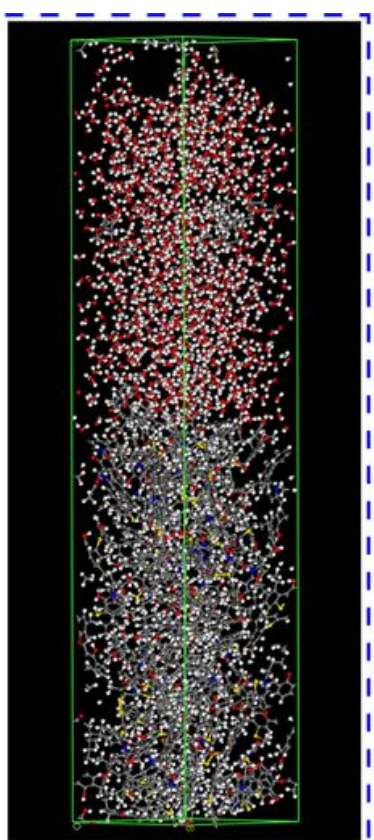

Final state

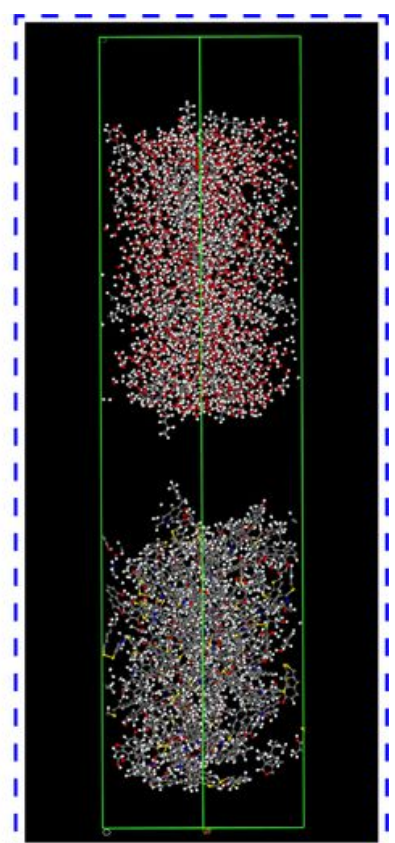

Initial state (a) System I

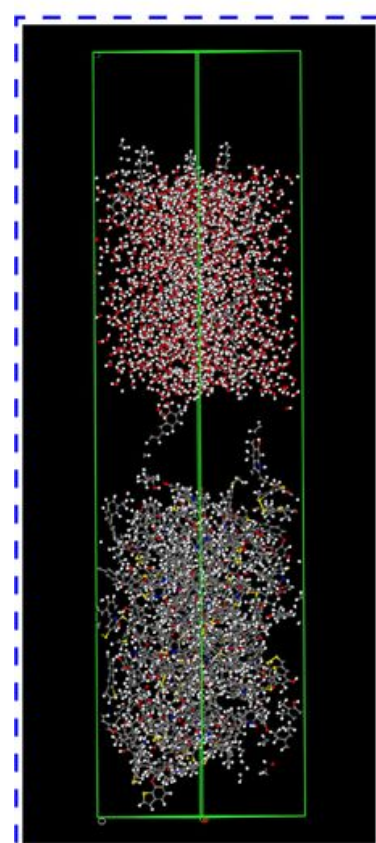

Initial state

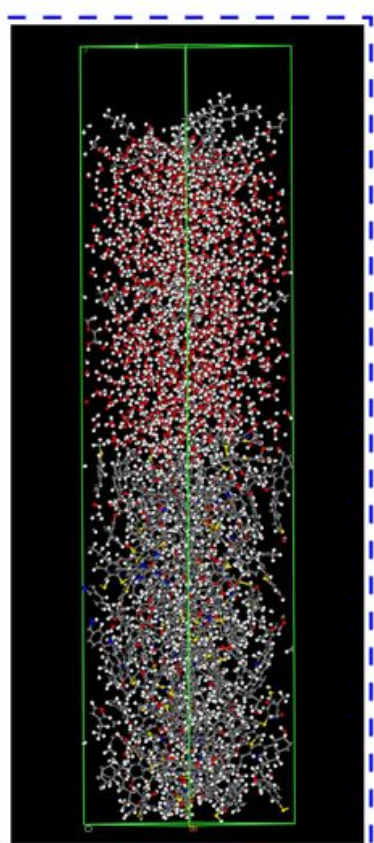

Final state

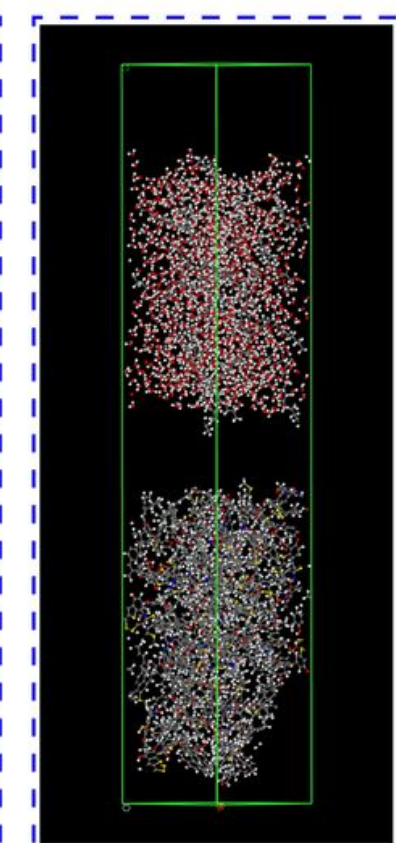

Initial state (b) System II

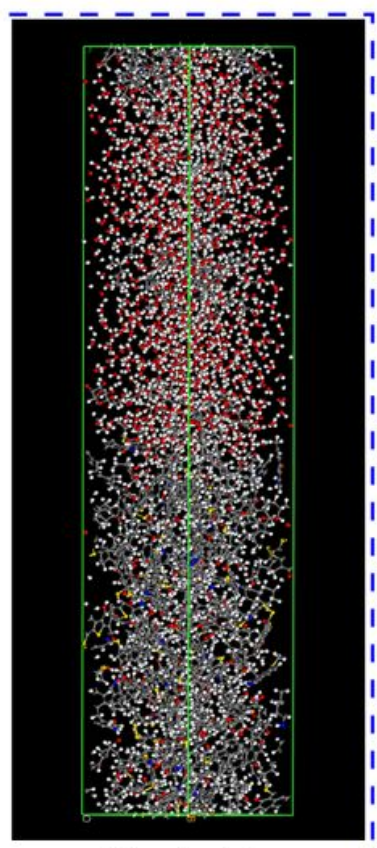

Final state (c) System III (d) System IV I 


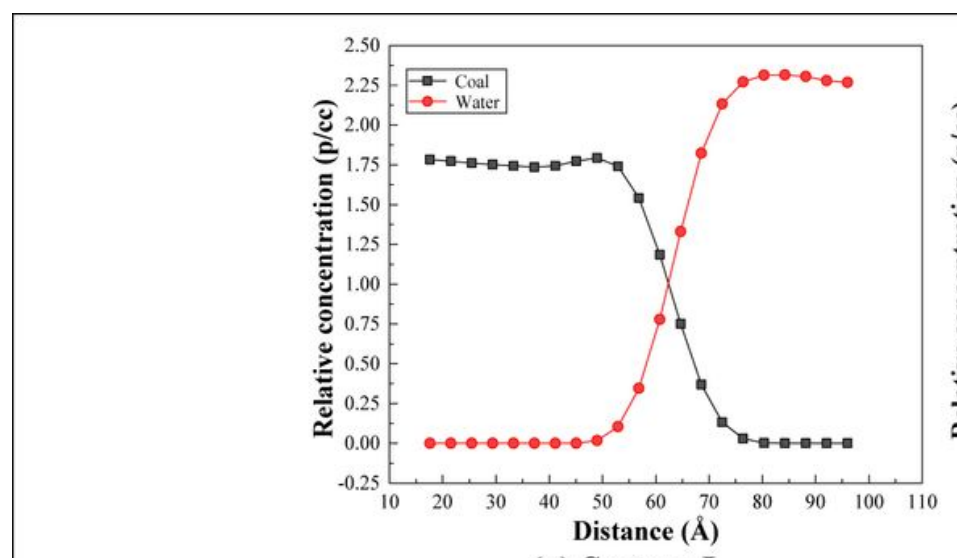

(a) System I

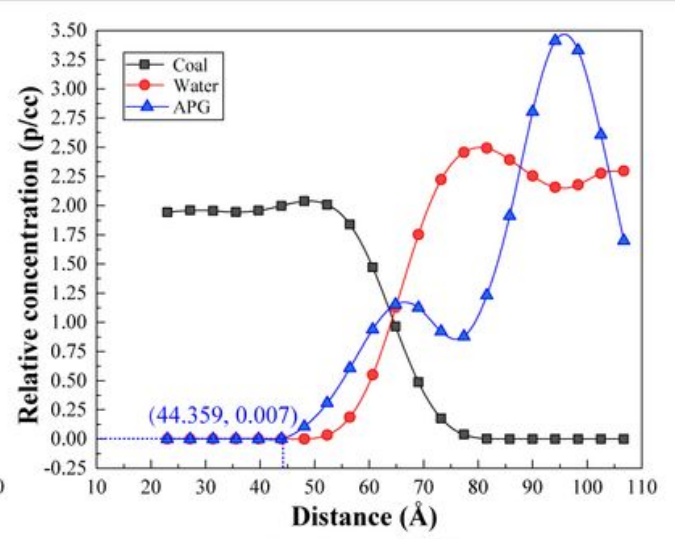

(b) System II

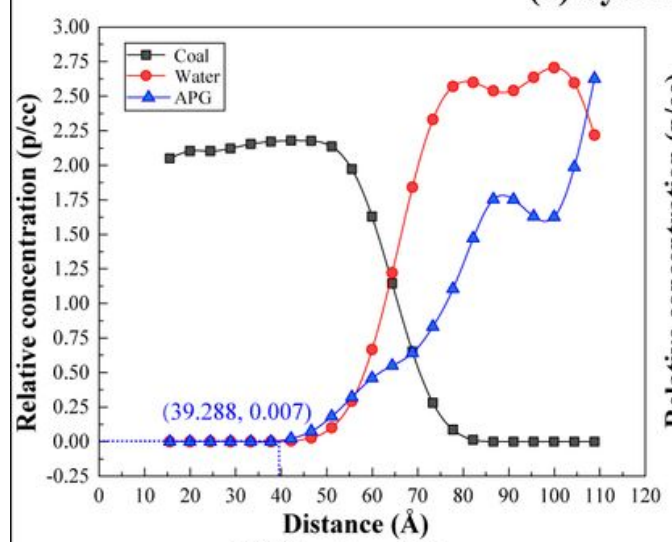

(c) System III

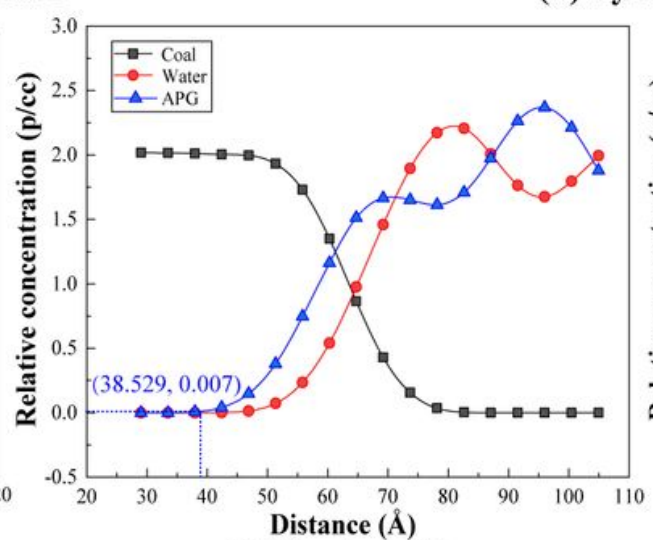

(d) System IV

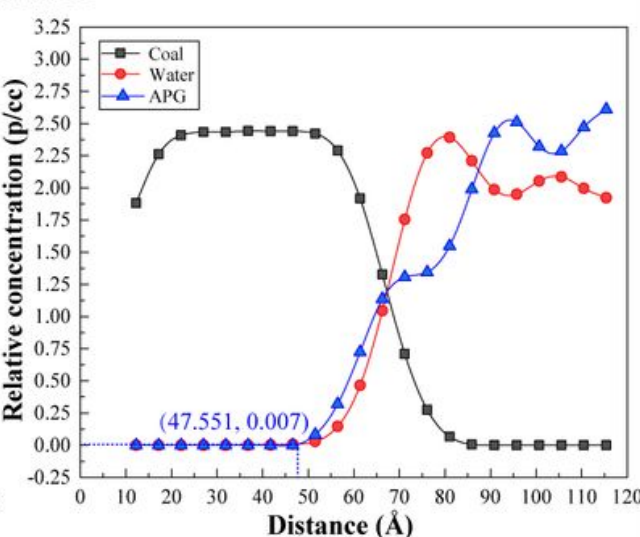

(e) System V

Figure 12

Relative concentration distribution of substances in different systems 

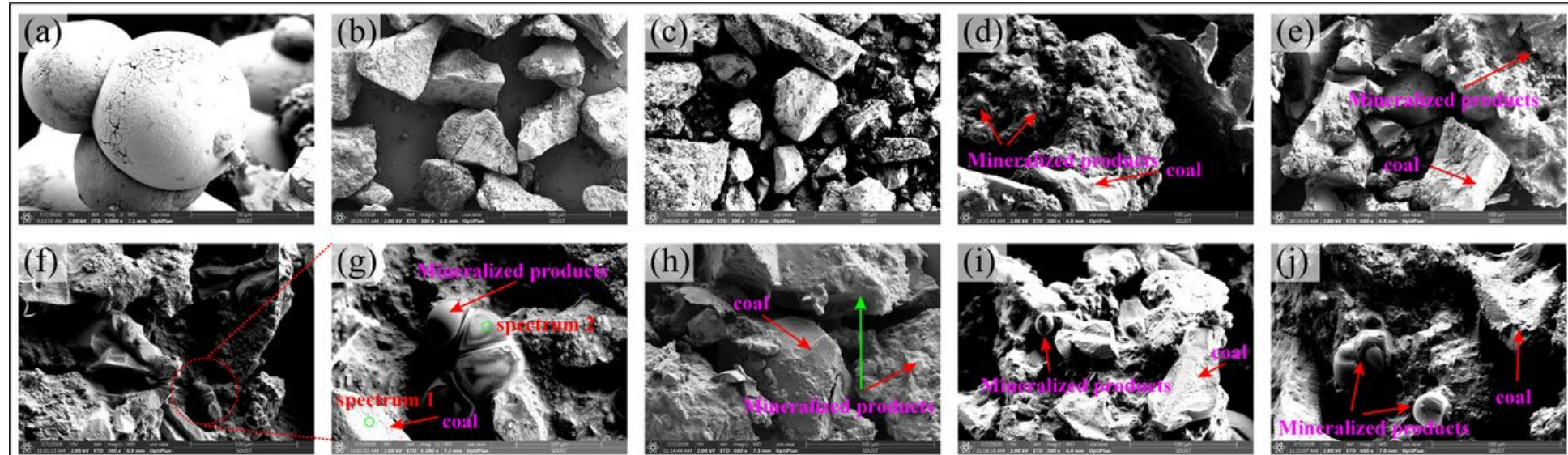

(k)

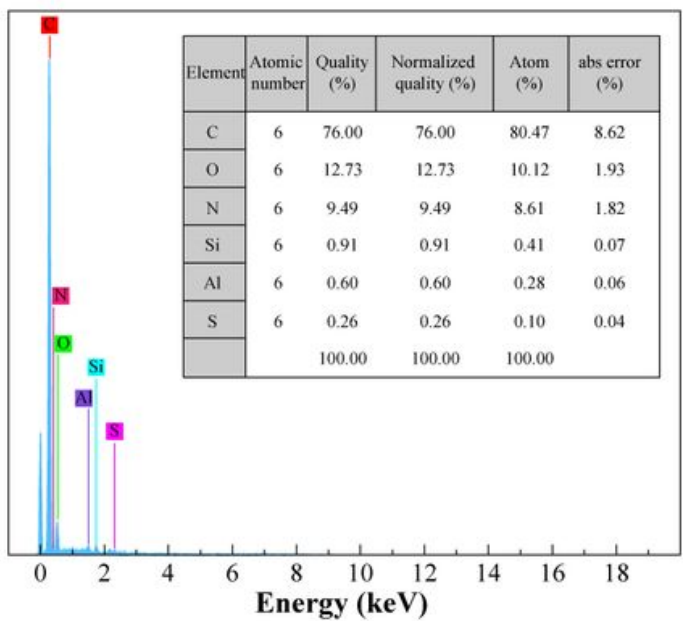

(1)
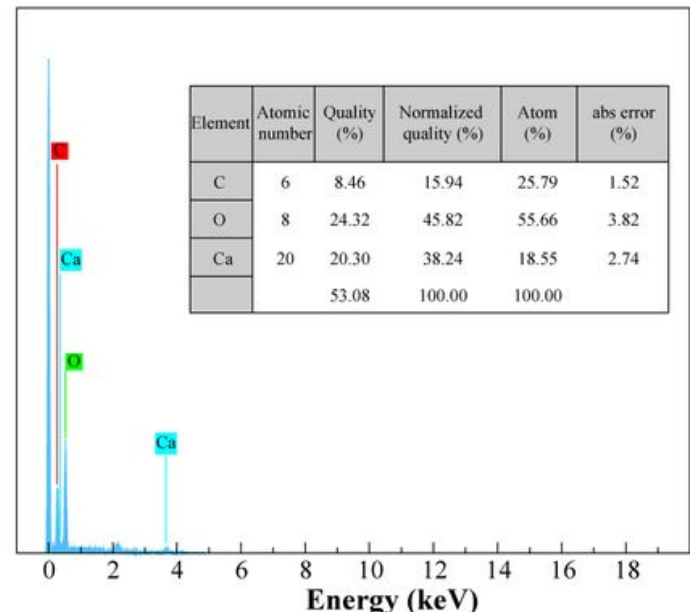

Figure 13

Micro-morphology and EDS analysis of different samples (a. Mineralized products; b. Coal dust; c. Coal dust of sample A-0; $d$. Coal dust on the surface of sample A-1; e. Coal dust at the bottom of sample A-1; $f$. Coal dust on the surface of sample A-2; g. Partial enlargement of coal dust on the surface of sample A-2; h. Coal dust at the bottom of sample A-2; i. Coal dust on the surface of sample A-3; j. Coal dust at the bottom of sample A-3; k. EDS analysis at spectrum 1 in Figure 13g; I. EDS analysis at spectrum 2 in Figure 13g) 


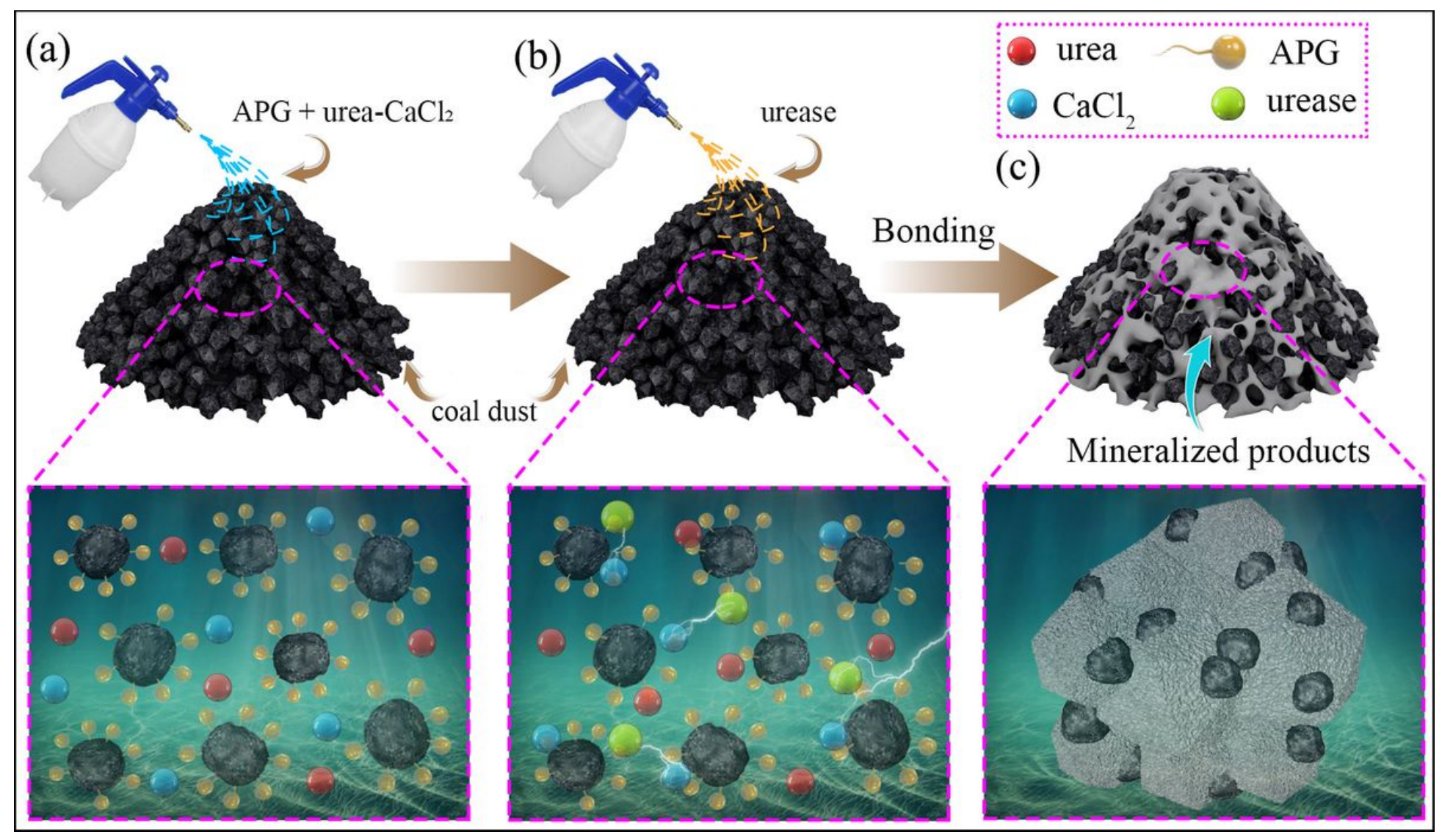

Figure 14

The process of coal dust being consolidated (a. APG improves the wettability of coal dust; b. Urease enters the coal dust; c. Coal dust is consolidated into a whole)

\section{Supplementary Files}

This is a list of supplementary files associated with this preprint. Click to download.

- SupplementaryMaterial.docx 